INEL-95/0445

\title{
CFD Model Development and Data Comparison for Thermal-Hydraulic Analysis of HTO Pilot Scale Reactor
}

R.J. Kochan

C.H. Oh

Published September 1995

Idaho National Engineering Laboratory Lockheed Idaho Technologies Company Idaho Falls, Idaho 83415

Prepared for the

U.S. Department of Energy

Assistant Secretary for Environmental Management

Under DOE Idaho Operations Office

Contifact No. DE-AC07-94ID13223 


\section{IDISCLAIMER}

Portions of this document may be illegible in electronic innage products. Images are produced from the best available original document. 


\begin{abstract}
The DOE Hydrothermal Oxidation (HTO) program is validating computational methods for use in scaling up small HTO systems; to production scale. As part of that effort, the computational fluid dynamics code FLUENT is being used to calculate the integrated fluid dynamics and chemical reactions in an HTO vessel reactor designed by MODAR, Inc. Previous validation of the code used data from a benchscale reactor. This reports presents the validation of the code using pilotscale (10 times greater throughjut than benchscale) data. The model for the pilotscale reactor has been improved based upon the benchscale data by including better fluid thermal properties, a better solution algorithm, addition of external heat transfer, investigation of the effects of turbulent flow, and, although not built into the computer model, a technique for using the calculated adiabatic oxidation temperatures for selecting initial conditions. Thermal results from this model show very good agreement with the limited test data from MODAR Run 920. In addition to the reactor temperatures, flowfield details, including chemical reaction distribution, and simulated salt particle transport were obtained. This model will be very beneficial in designing and evaluating larger commercial scale units. The results of these calculations indicate that for model validation, more accurate boundary conditions need to be measured in future test runs.
\end{abstract}

\title{
DISCLAIMER
}

This report was prepared as an account of work sponsored by an agency of the United States Government. Neither the United States (Jovernment nor any agency thereof, nor any of their employees, makes any warranty, express ir implied, or assumes any legal liability or responsibility for the accuracy, completeness, or Iısefulness of any information, apparatus, product, or process disclosed, or represents that its use would not infringe privately owned rights. Reference herein to any specific commercial product, process, or service by trade name, trademark, manufacturer, or otherwise does not necessarily constitute or imply its endorsement, recommendation, or favoring by the United States Government or any agency thereof. The views and opinions of authors expressed herein do not necessarily state or reflect those of the United States Government or any agency thereof. 


\section{SUMMARY}

In the Hydrothermal Oxidation (HTO) process (also referred to as the Supercritical Water Oxidation (SCWO) process), organics are oxidized in the presence of air and water at conditions above the critical temperature and pressure of water. This process is being evaluated by the U.S. Department of Energy for extension to the treatment of mixed wastes. Benchscale and pilotscale units, treating surrogate mixed hazardous wastes, have proven to be effective waste reducers. It is desired that they be scaled up to the size of a production facility.

The technical issues of scale up, chemical corrosion mitigation, salt formation and separation, and complex chemical kinetics need to be resolved in order to apply the smaller scale results directly to the larger units. At this time, simple geometric or flow scaling criteria are being used to extend the small scale results to the larger scales. This is not adequate for optimal scale up of the process and component design because of the strong coupling of the thermal-hydraulics and the chemical kinetics in the HTO process. The flow and chemical kinetics regimes in the small scale units are not identical to those of large production facilities; in some cases, the geometric configurations will not even be the same.

To use the small scale results properly in designing the larger scale units, it is necessary to create coupled flow-chemical kinetics models of the benchscale and pilotscale HTO reactors, validate their accuracy against measured data, and then use the models to extrapolate the results to the larger scales. Then, when the larger scale plant is built and tested, the extrapolation procedures can be further validated for sujsequent use. At the larger scale, this method of optimizing and validating designs with detailed computer models will save considerable resources over the approach of building the reactor first and then modifying it or rebuilding it if the design is not adequate.

The detailed flow-chemical kinetics models should also provide the capability of modeling the effects of chemical corrosion and salt formation, phenomena which are strongly coupled to the flow and chemical compositions. Simple scaling will not be able to predict the magnitudes and extent of these effects. Extrapolation from a specific test condition to another would be difficult, if not impossible, without a coupled code.

This report presents an extension of a computational fluid dynamics (CFD) model of a MODAR benchscale vessel reactor to a MODAR pilotscale vessel reactor. Calculations were extended using this CFD model to investigate the effect of different chemical kinetics reaction rates on the thermal-hydraulics in the reactor vessel. Also, a brief study of the turbulent transport of small particles (representing precipitated salt particles or other small solid particles) in the vessel flowfield was performed to investigate the potential locations of solids deposition.

Results from this model are compared with test data from the MODAR reactor and show very good agreement with the limited temperature data. It should be noted that MODAR's temperature data were not collected for CFD verification. Data collection requirements for safe and efficient HTO operation are very different from those needed for CFD verification. It is recommended that CFD specific boundary data be collected in future tests to help minimize uncertainties in model verification. 


\section{CONTENTS}

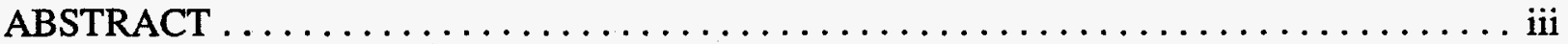

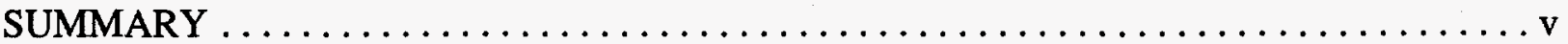

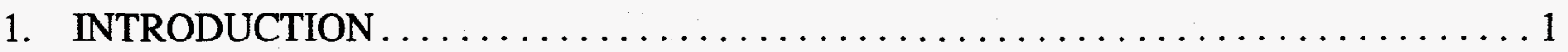

2. HTO VESSEL REACTOR MODEL AND ASSUMPTIONS $\ldots \ldots \ldots \ldots \ldots \ldots \ldots$

2.1 Pilot Scale Reactor Descrijtion and Operation ...................... 3

2.2 Vessel Reactor Discretization and Boundary Conditions $\ldots \ldots \ldots \ldots \ldots \ldots \ldots$

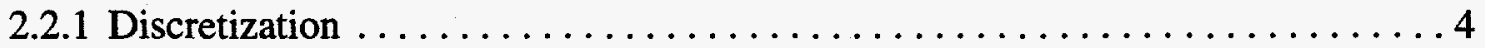

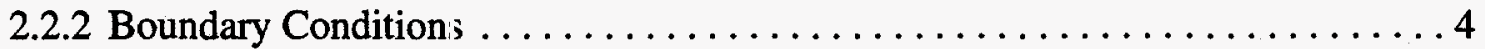

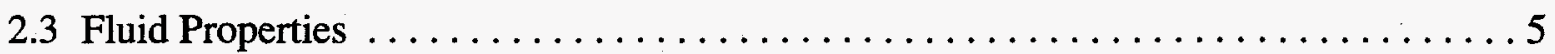

2.3.1 Thermodynamic and Transport Properties .................... 5

2.3.2 Reaction Rate Constants . . . . . . . . . . . . . . . . . . . . . . . . 9

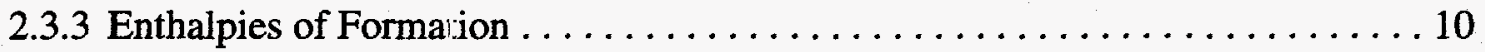

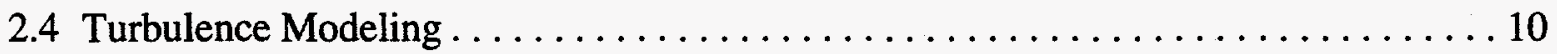

3. MODAR RUN 920 RESULT COMPARISONS $\ldots \ldots \ldots \ldots \ldots \ldots \ldots \ldots \ldots \ldots \ldots \ldots \ldots \ldots$

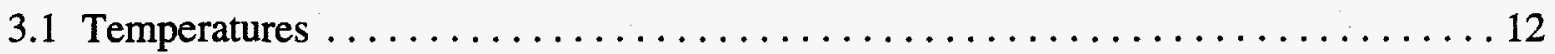

3.1.1 Adiabatic Reaction Temperatures......................... 12

3.1.2 Fluid Temperatures .............................. 14

3.2 Vessel Reactor Characteristics . . . . . . . . . . . . . . . . . . . . 16

3.2.1 Recirculation Pattern. . . . . . . . . . . . . . . . . . . . . . . . . 16

3.2.2 Fluid Residence Times . . . . . . . . . . . . . . . . . . . . . . . 16

3.2 .3 Nozzle Mixing Zone . . . . . . . . . . . . . . . . . . . . . . . 18

3.2.4 Effect of Smoothing the Water Heat Capacity Curve $\ldots \ldots \ldots \ldots \ldots \ldots \ldots 18$

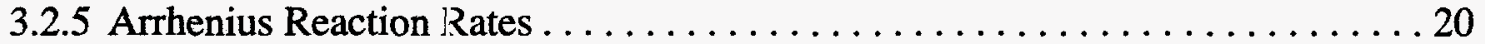

3.2.6 Particle Trajectories ................................... 24

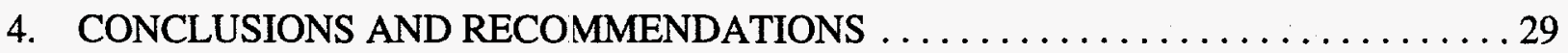

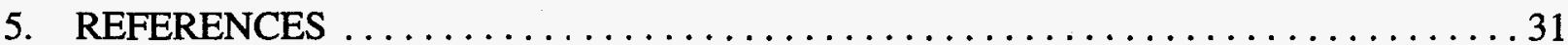




\section{FIGURES}

1. Process flow sheet for MODAR pilot scale reactor test. $\ldots \ldots \ldots \ldots \ldots \ldots \ldots \ldots \ldots$

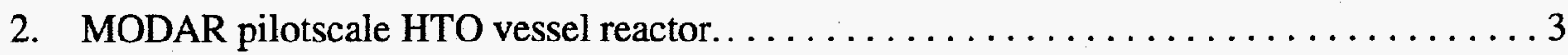

3. Specific heats of HTO fluids. $\ldots \ldots \ldots \ldots \ldots \ldots \ldots \ldots \ldots \ldots \ldots \ldots \ldots \ldots$

4. Densities of HTO fluids. $\ldots \ldots \ldots \ldots \ldots \ldots \ldots \ldots \ldots \ldots \ldots \ldots \ldots \ldots$

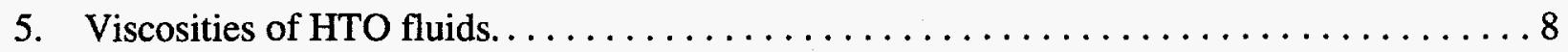

6. Thermal conductivities of HTO fluids. $\ldots \ldots \ldots \ldots \ldots \ldots \ldots \ldots \ldots \ldots$

7. Comparison of water specific heat obtained from NBS steam tables with the approximation used in the FLUENT model at 3400 psia and $500-800 \mathrm{~K} \ldots \ldots \ldots \ldots$

8. Adiabatic reaction temperatures for MODAR Run $920,125 \mathrm{~g} / \mathrm{min}$ IPA in core,

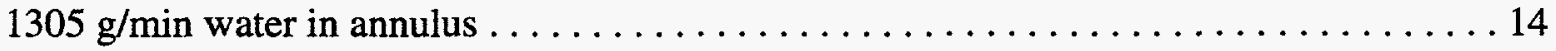

9. FLUENT predicted fluid temperatures ( C) for MODAR Run $920 \ldots \ldots \ldots \ldots \ldots$

10. Comparison of MODAR near-wall test data with FLUENT predicted temperatures. . . . . 15

11. FLUENT predicted streamfunctions for MODAR Run $920 \ldots \ldots \ldots \ldots \ldots \ldots$

12. FLUENT predicted streaklines for a 40 second time period. $\ldots \ldots \ldots \ldots \ldots \ldots$

13. Thermal and hydraulic mixing downstream of nozzle. Flow is well mixed both thermally and hydraulically by about 1 reactor diameter from nozzle. . . . . . . . . . . 19

14. Regions of the reactor with temperatures between $327 \mathrm{C}$ and $427 \mathrm{C}$ showing the regions of approximate water specific heats. Peak $c_{p}$ is at 379 C. . . . . . . . 20

15. Reaction rate distribution for baseline Arrhenius rate equation for IPA. . . . . . . 21

16. Variations of Arrhenius reaction rate curves considered in this study. MODAR's IPA curve is the baseline. Case 2 is $10 \mathrm{X}$ higher than the baseline. Case 3 is $0.1 \mathrm{X}$ the baseline. Case 4 has a steeper slope with the same value as the baseline at $600 \mathrm{C}$

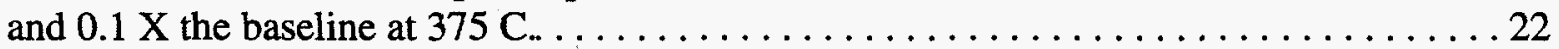

17. Comparison of IPA reaction rates and mass fractions for Cases 1-4. IPA reaction rates are shown in the range from -0.335 to $0 \mathrm{~kg} / \mathrm{m}^{3}-\mathrm{sec}$ and are shown on the right half of each figure. Mass fractions are shown in the range from $10^{-2}$ to $10^{-10}$ and are shown on the left half of each figure. The inlet mass fraction of IPA is $0.1037 \ldots \ldots \ldots \ldots \ldots 23$ 
18. Trajectories of $20,40,60,80$, and $100 \mu$ salt particles precipitating out in the vessel reactor. These calculations use the mean fluid velocities and neglect the effect of turbulence. . . . 25

19. Typical trajectories of three $20 \mu$ (top) and three $500 \mu$ (bottom) particles with the effects of turbulence included. Release point is on reactor centerline. . . . . . . . 26

20. Salt particle impact zones to study the effect of turbulent flow on particle transport. . . 26

\section{TABLES}

1. Enthalpies of formation for HT'O species. $\ldots \ldots \ldots \ldots \ldots \ldots \ldots \ldots \ldots \ldots \ldots \ldots$

2. Wall impact summary for $5-101) 0 \mu 50 \%$ void salt particles. Each column represents a total of 100 tries. Injection location is in nozzle diameters from reactor centerline at an axial location of 1.2 nozzle diameters from the nozzle exit plane........... 27 


\section{Preliminary Code Validation for Thermal-Hydraulic Analysis of HTO Pilot Scale Reactor}

\section{INTRODUCTION}

Reference 1 details the analytical modeling requirements for the thermal hydraulic analysis of a Hydrothermal Oxidation (HTO; pilot plant using a computational fluid dynamics (CFD) computer code. Reference 2 presen ts the rationale for selecting the FLUENT ${ }^{3}$ CFD code for modeling the combined flow and chemical kinetics of a vessel type HTO reactor and initiates the validation of a FLUENT CFD model by using test data from a MODAR bench scale reactor.

This report extends the FLUENT CFD model validation from the benchscale reactor used in Reference 2 to a larger pilot scale reactor with a somewhat different configuration. A process flow sheet of the pilot scale test conjiguration is shown in Figure 1. Test data and configuration details for this reactor were again provided to the Idaho National Engineering Laboratory (INEL)

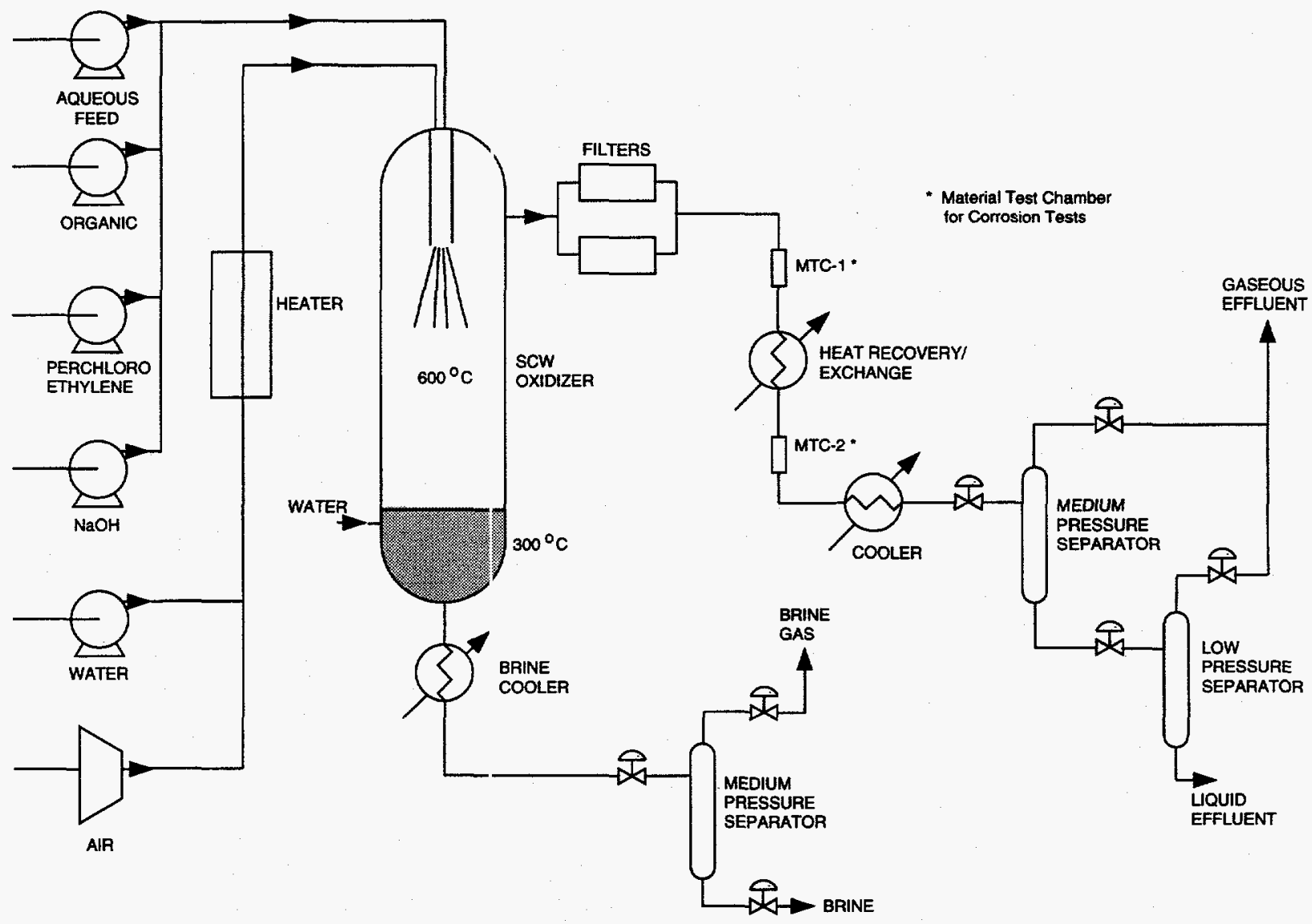

Figure 1. Process flow sheet for MODAR pilot scale reactor test. 
by MODAR under a cooperative agreement for CFD model development and validation. The computational results are compared with the test data and a detailed discussion of important modeling considerations is provided. Recommendations for future work to enhance the model validation are given. 


\section{HTO VESSEL REACTOR MODEL AND ASSUMPTIONS}

Much of the model geometry and boundary conditions used in this study is MODAR proprietary information and must be protected as such; to facilitate this the proprietary information is omitted from this report. The figures have been scaled and truncated to protect MODAR's proprietary geometry. If proprietary information is needed, it must be obtained from MODAR, Inc. Non-proprietary assumptions used are discussed below.

FLUENT solves the full Navier-Stokes equations for compressible chemically reacting flows as described in Reference 3. 'The axisymmetric option of the code was used in this study.

\subsection{Pilot Scale Reactor Description and Operation}

Figure 2 shows a sketch of the MODAR pilotscale HTO reactor that was used in Run 920. This test investigated the oxidation of isopropyl alcohol (IPA) by air in a supercritical water environment. The IPA and water equivalent to a total waste flow of $500 \mathrm{gal} /$ day were introduced into the reactor at high pressure $\left(3400 \mathrm{p}\right.$;ia) and low temperature $\left(50^{\circ} \mathrm{C}\right)$ in the center of the coaxial nozzle, while high temperature $\left(620^{\circ} \mathrm{C}\right)$ air and water at the same pressure were introduced in the annulus of the nozzle.

In actual operation, the brine level is maintained by the use of a standpipe and a net brine removal (more water was removed via the standpipe than was added as brine make up. The net downflow is limited to a small fraction of the feed nozzle flow. This was modeled by specifying

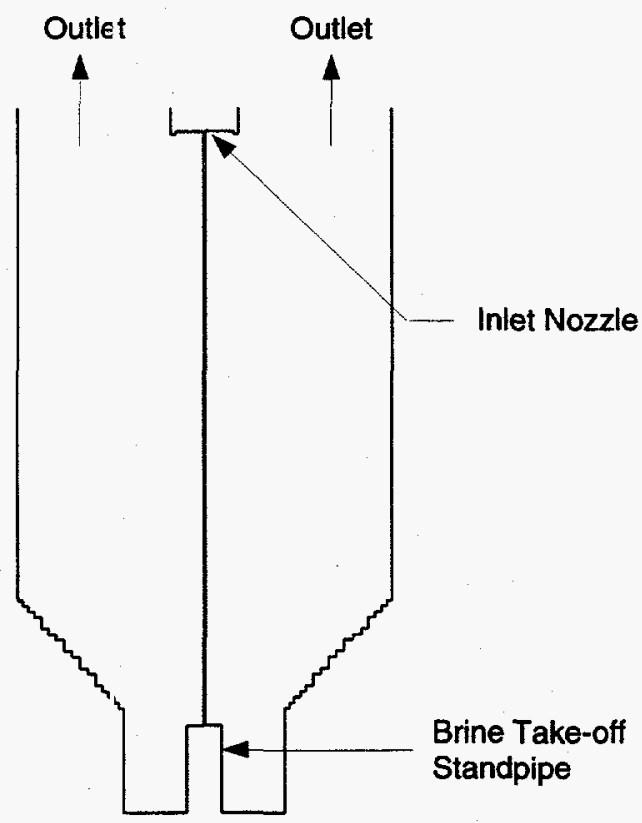

Figure 2. MODAR pilotscale HTO vessel reactor. 
a fluid velocity into the standpipe that removes the desired mass flow of water.

In the actual reactor, the high temperature effluents exit through a single circular nozzle in the upper end of the reactor. This outlet was approximated by a circumferential slit with the same cross-sectional area to keep the model axisymmetric. Based on post run observations and previous modeling results ${ }^{4}$, MODAR believes that the feed jet dominates the reactor flow patterns. The non-symmetrical exit geometry does not significantly change the flow pattern in the reacting zone. Nonetheless, we plan to verify this numerically at a later date using a simplified, non-reacting 3-D model.

The test data from MODAR Run 920 with a 1:1 annulus SCW to core flow ratio was obtained from proprietary MODAR reports ${ }^{\mathrm{a}, \mathrm{b}}$ for conditions after about six hours of a quasisteady state run. Temperatures were measured in the reactor fluid a short distance from the reactor wall. These measurements were made at 18 axial locations from near the inlet nozzle to positions in the brine pool.

\subsection{Vessel Reactor Discretization and Boundary Conditions}

\subsubsection{Discretization}

The MODAR pilotscale vessel reactor geometry modeled in this study is proprietary and was provided by MODAR. The discretized domain consists of 209 axial x 35 radial (7,315 total) cells representing axisymmetrically one-half of the reactor. The thin inlet nozzle annulus was modeled by a single cell, while the larger inlet nozzle core flow was modeled by 5 cells. The upper effluent outlet and brine inlets were modeled by a single cell and the brine takeoff was modeled by 2 cells. For this development of the pilot scale model, the lower conical section was modeled by a simple step-wise grid. Because the fluid velocities are low in this region, the overall calculations are not significantly affected by this assumption.

\subsubsection{Boundary Conditions}

The FLUENT boundary conditions for this study represent the conditions of the steady state portion of MODAR Run $920^{\circ}$, the oxidation of IPA in supercritical water by air. The boundary conditions used and rationale for their selection are detailed below:

1. The vessel was oriented vertically with the inlet flows injected downward. Gravitational forces were included.

a. A. Bourhis, MODAR Letter to T. Charlton, "Summaries of Four MODAR Experiments," MODAR confidential information, August 24, 1994.

b. A. Bourhis, MODAR Letter to T. Charlton, "Additional Pilot Scale Data - Attachments A - H“, MODAR confidential information, February 8, 1995. 
2. A symmetry boundary condition was used at the vessel centerline.

3. The core inlet flow measured by MODAR consists of $125 \mathrm{~g} / \mathrm{min}$ of IPA and $1180 \mathrm{~g} /$ min of water at $3,400 \mathrm{psia}$ and $50^{\circ} \mathrm{C}$. During the simulation, the core water was used as an adjustable parameter to match the simulated final temperatures to the measured temperatures. This is discussed in detail in the results section. A uniform velocity profile was assumed at the core nozzle exit (i.e., to simplify the calculations, boundary layer development in the nozzle was neglected). The core inlet turbulence intensity is assumed to be $5 \%$.

4. The specified annular flow consists of $1539 \mathrm{~g} / \mathrm{min}$ of air $\left(21 \% \mathrm{O}_{2}\right.$ and $\left.79 \% \mathrm{~N}_{2}\right)$ at $3,400 \mathrm{psia}$ and $620^{\circ} \mathrm{C}$. An annulus water flowrate of $1305 \mathrm{~g} / \mathrm{min}$ was used (a 1:1 SCW to core flow ratio ${ }^{b}$ ). A uniform velocity profile was assumed at the annular nozzle exit. The annulus inlet turbulence intensity is assumed to be $5 \%$.

5. The reactor was insulated from the top head down to the conical section with approximately 3 inches of vermizulite to reduce the heat losses to the surroundings. A heat transfer coefficient of $1.95 \mathrm{w} / \mathrm{m}^{2}-\mathrm{K}$ and an effective ambient temperature of $27^{\circ} \mathrm{C}$ were used to simulate these conditions.

6. The conical section and the bottom cylinder were left uninsulated. For the simulation a linear wall temperature distribution was assumed in this lower section. The wall temperature was assumed to be $600^{\circ} \mathrm{C}$ at a location 1 foot above the conical section and it linearly decreased to $200^{\circ} \mathrm{C}$ at the bottom of the reactor. This profile was chosen to mimic the near-wall temperature measurements.

7. A brine makeup inlet flow of pure water at $27^{\circ} \mathrm{C}$ was injected into the lower cylindrical section to establish a ?ool of subcritical water in this region. A constant exit velocity specified at the top of a brine standpipe was adjusted to remove the required amount of water from the top of the brine pool. Note that other gases are also removed with the water (water is about $75 \%$ by mass of the total outlet flow).

\subsection{Fluid Properties}

\subsubsection{Thermodynamic and Transport Properties}

The critical point of water is at $3,206 \mathrm{psia}(22.1 \mathrm{MPa})$ and $374^{\circ} \mathrm{C}$. An HTO reactor typically operates at a pressure somewhat higher than the critical pressure; the MODAR reactor, simulated in this report, was operated at a pressure of $3400 \mathrm{psia}(23.4 \mathrm{MPa})$.

The five chemical species considered in this application are IPA, water, carbon dioxide, oxygen, and nitrogen. Thermodynamic and transport properties needed for each species are the com- 
ponent densities, specific heats, viscosities, and thermal conductivities. These properties were obtained from the Aspen code ${ }^{5}$ as a function of temperature in the range of $300 \mathrm{~K}$ to $1500 \mathrm{~K}$ and at a constant pressure of $3400 \mathrm{psia}$. The vessel reactor operates with a relatively low pressure drop; the assumption of constant pressure properties will not introduce significant error into the calculations. Water properties were calculated using the NBS correlations in the Aspen code, while the properties of the other fluids were calculated with the SR-Polar option. These properties are improved from those used in the earlier study in Reference 2 as they are all obtained for the system pressure of $3400 \mathrm{psia}$ (Reference 2 used water properties at $3500 \mathrm{psia}$ ) and they are extended to slightly lower temperatures than the $366 \mathrm{~K}$ of Reference 2 .

Figure 3 through Figure 6 shows the specific heat, density, viscosity, and thermal conductivity of all the species used in this study, as well as those of ethanol (ethanol was used in the bench-scale study from Figure 2 ).

FLUENT computes the mixture density from the individual specie densities as:

$$
\rho=\frac{1}{\sum_{i} \frac{m_{i}}{\rho_{i}}}
$$

where $m_{i}$ is the mass fraction and $\rho_{i}$ is the density of species $i$.

FLUENT computes the mixture heat capacity, viscosity, and thermal conductivity (shown for heat capacity) as:

$$
c_{p}=\sum_{i} m_{i} c_{p, i}
$$

where $c_{p, i}\left(\right.$ or $\mu_{i}$ or $k_{i}$ ) are the specie properties.

These are ideal mixing assumptions and may not be strictly accurate at these supercritical conditions. It is recommended that this entire category of multicomponent supercritical fluid properties be investigated in detail. This can be done less expensively in a small scale laboratory experiment rather than in the more expensive SCWO experiments.

Figure 7 shows a comparison between the approximations of specific heat of water used in this study and the values predicted using the ASPEN NBS steam tables in Reference 5 . Figure A.37 in Reference 6 shows that the NBS steam tables are very accurate in the vicinity of the critical point. As was done in Reference 2, the specific heat of water near the critical point was modified to enhance the stability and convergence of the numerical solution. Whereas the approximation used in Reference 2 was a simple triangular spike over the temperature range of $600 \mathrm{~K}$ to $700 \mathrm{~K}$, the approximation used in this study was a somewhat rounder curve in that the integral of the curve was the same as that from the NBS curve so that temperatures in the attempt to improve the stability of the solution. The approximate curve was computed to ensure reactor in regions outside this range are calculated accurately. The impact of this approximation on the 
calculated temperature domain will be discussed later.

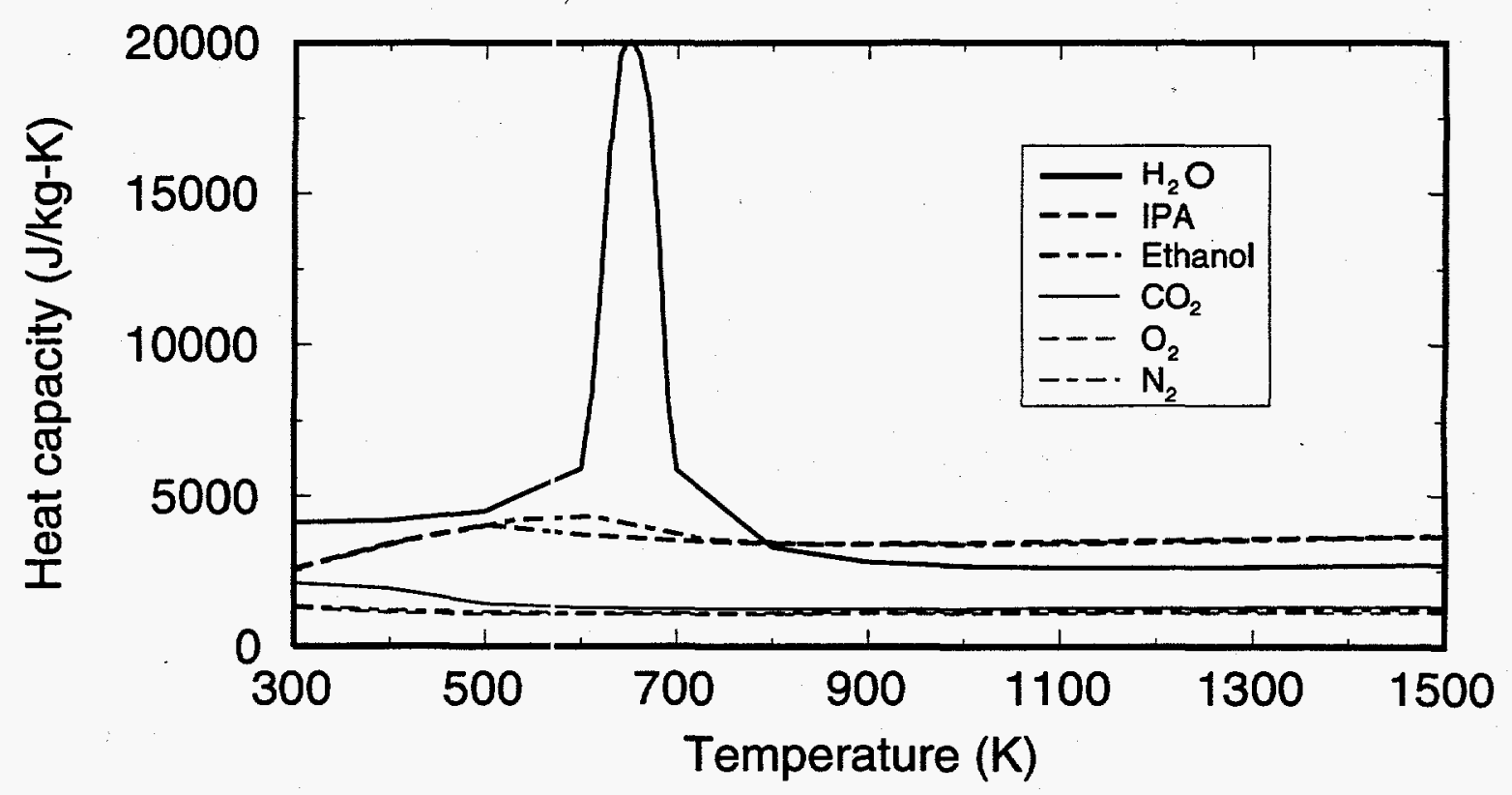

Figure 3. Specific heats of HTO fl lids.

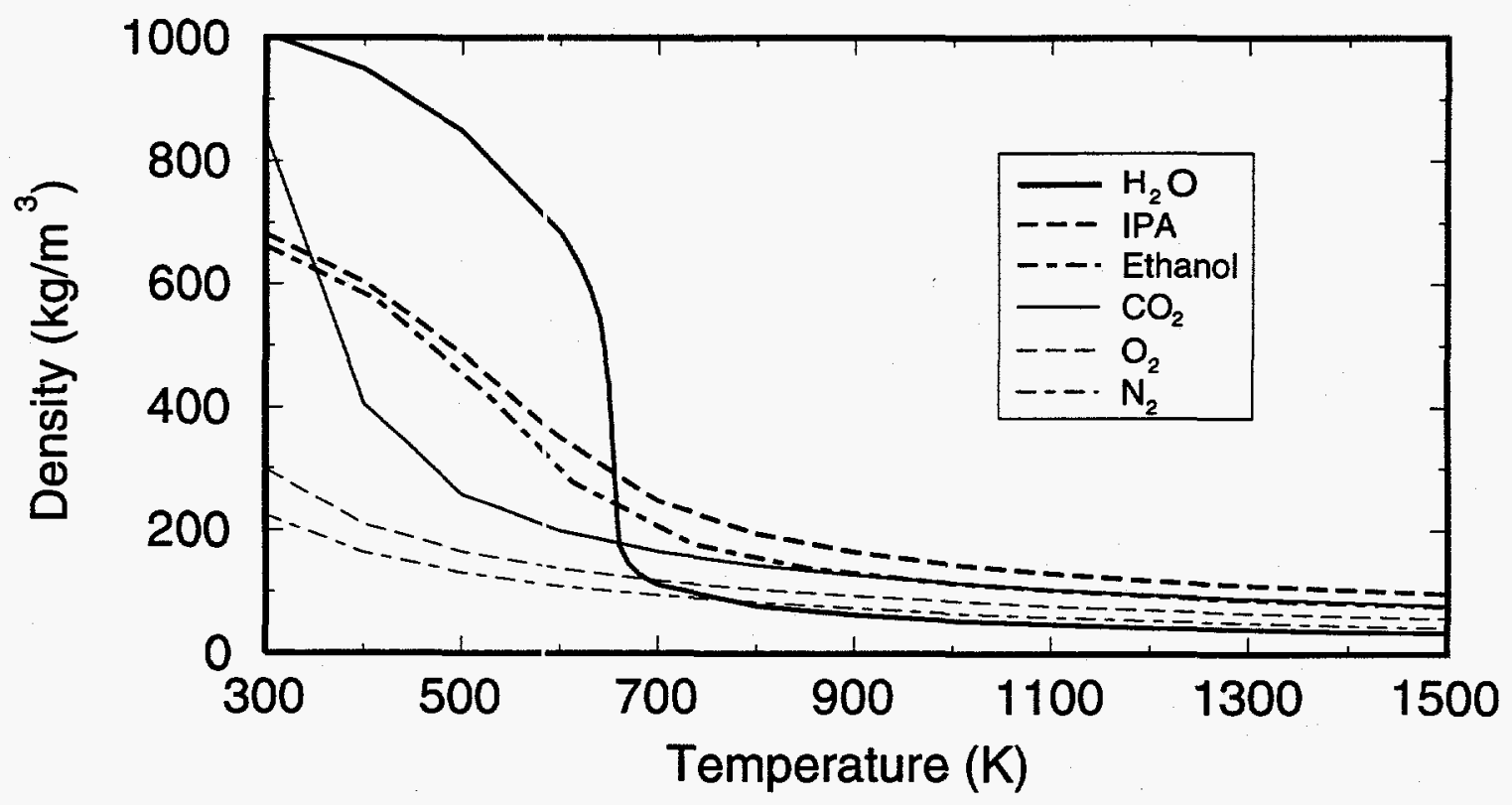

Figure 4. Densities of HTO fluids. 


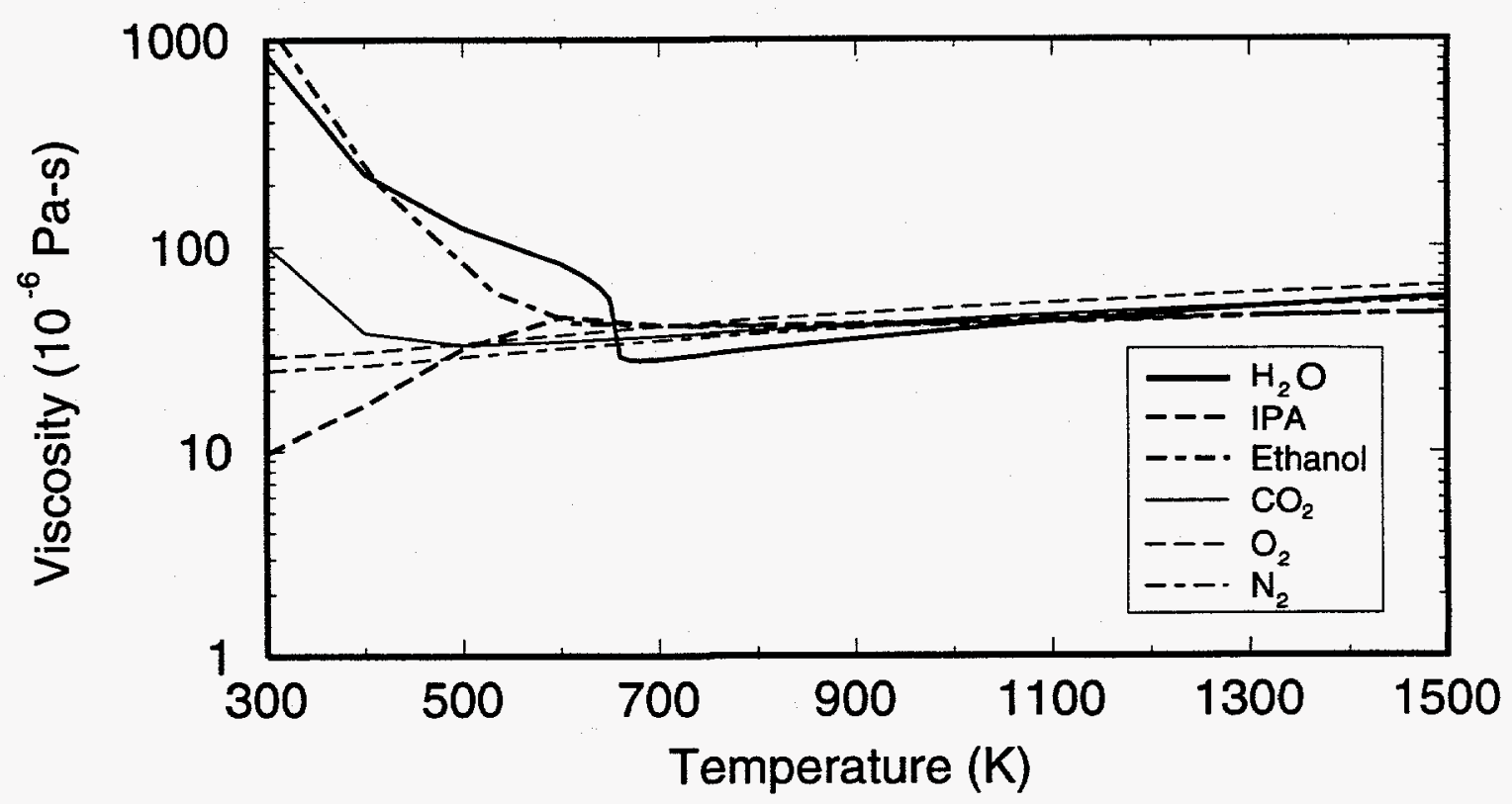

Figure 5. Viscosities of HTO fluids.

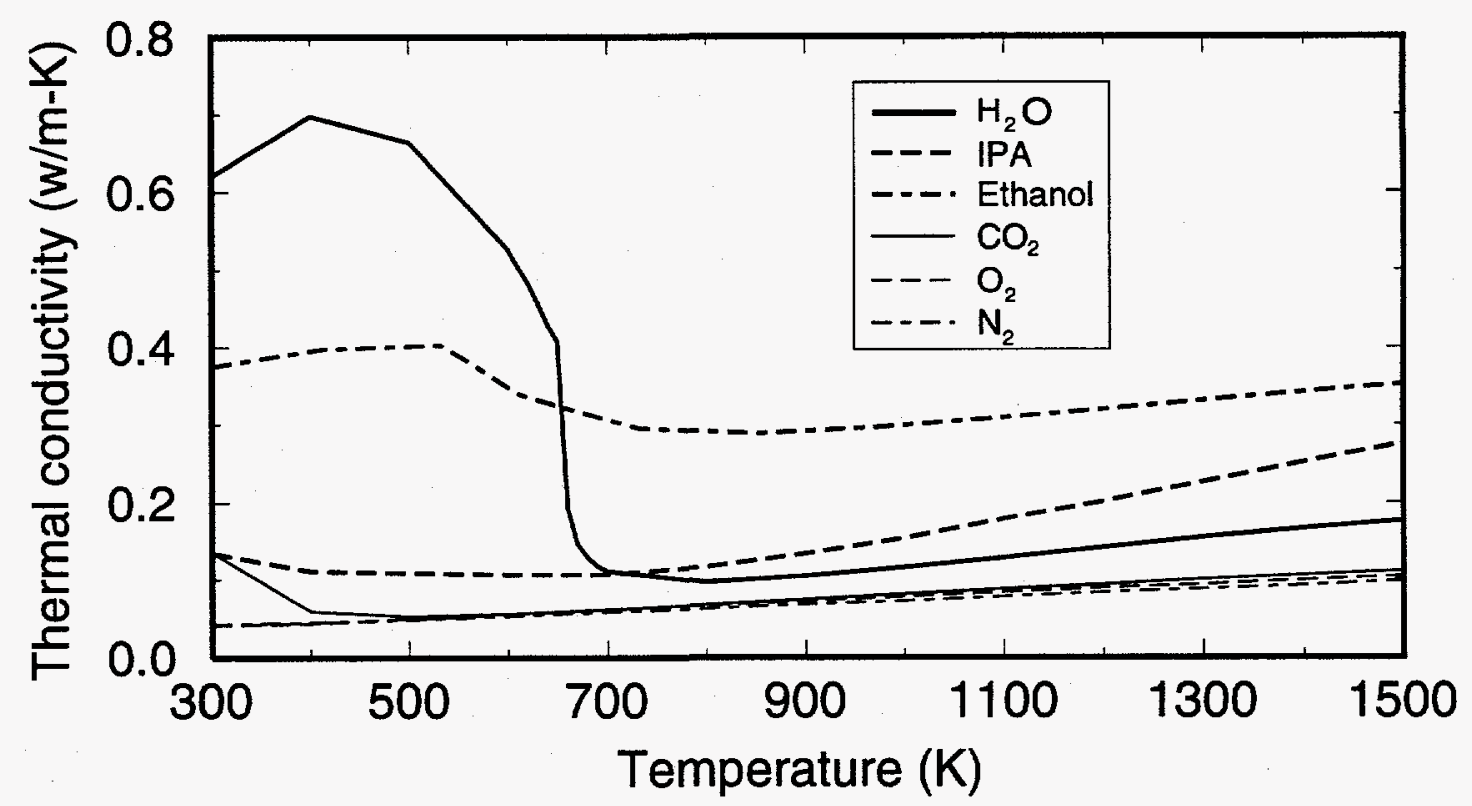

Figure 6. Thermal conductivities of HTO fluids. 


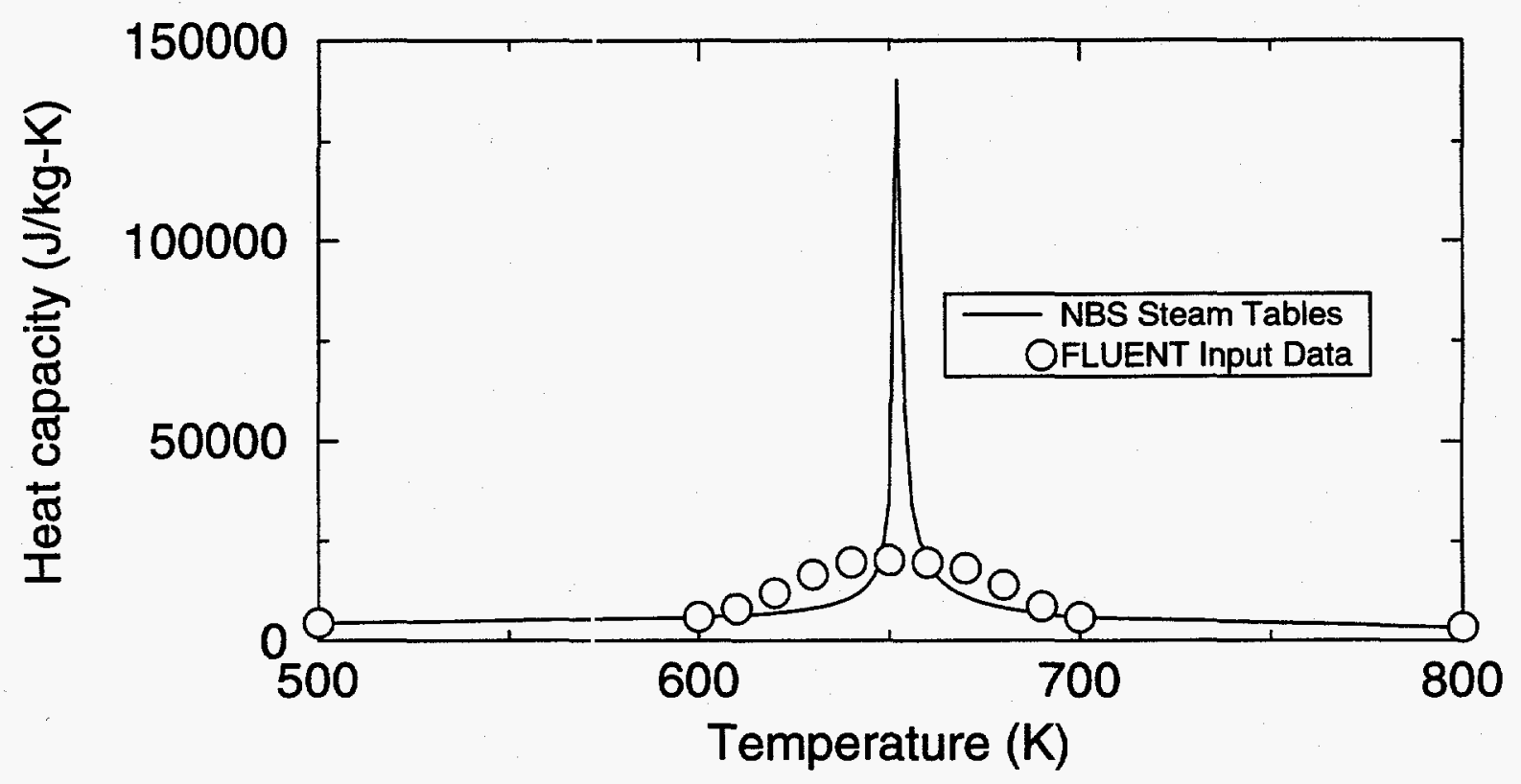

Figure 7. Comparison of water specific heat obtained from NBS steam tables with the approximation used in the FLUENT model at 3400 psia and 500-800 K.

\subsubsection{Reaction Rate Constants}

The IPA kinetics used in this s:udy approximates the multistep IPA oxidation reaction by the single step reaction

$$
\mathrm{C}_{3} \mathrm{H}_{7} \mathrm{OH}+\frac{9}{2} \mathrm{O}_{2} \rightarrow 3 \mathrm{CO}_{2}+4 \mathrm{H}_{2} \mathrm{O}
$$

The reaction rate approximation used in the FLUENT model was first order in IPA with a two parameter Arrhenius rate constiant:

$$
R_{I P A}=-M_{I P A} C_{I P A} A_{I P A} \exp \left(-\frac{E_{I P A}}{R_{u} T}\right)
$$

where $R_{I P A}$ is the mass rate o: generation of IPA in each cell, $M_{I P A}$ is the molecular weight of IPA, $C_{I P A}$ is the molar concentration of IPA, $R_{u}$ is the universal gas constant, and $T$ is the fluid temperature.

There is very little kinetic dat: on IPA oxidation in the literature. The Arrhenius kinetic rate constants used for this study were provided by MODAR. This data was regressed from non-iso- 
thermal pipe reactor temperature data, where a cold $\left(25^{\circ} \mathrm{C}\right) \mathrm{IPA} /$ water stream was mixed and reacted with a hot $\left(550^{\circ} \mathrm{C}\right)$ water/air stream. MODAR has indicated to us that this data may not meet the usual standards associated with kinetics studies.

Data obtained from similar ethanol tests were also regressed to obtain Arrhenius rate expressions. When compared to data measured by Helling and Tester ${ }^{7}$, the rates at $600^{\circ} \mathrm{C}$ agreed well but the MODAR data was 4-5 orders of magnitude higher at near critical conditions. This difference is believed to be due to non-isothermal inlet conditions in the MODAR test. We investigated the effect of these two rate constants on the reaction zone shapes; these results will be discussed later.

\subsubsection{Enthalpies of Formation}

The formation enthalpies for all species entering into the chemical reactions, together with the reference temperatures at which these are defined, are required in the FLUENT model. The values used in these calculations were obtained from Reference 8 and are shown in the table below:

Table 1. Enthalpies of formation for HTO species.

\begin{tabular}{|c|c|c|}
\cline { 2 - 3 } & $\begin{array}{c}\text { Formation enthalpy } \\
(\mathrm{J} / \mathrm{kmol})\end{array}$ & $\begin{array}{c}\text { Reference } \\
\text { temperature } \\
(\mathrm{K})\end{array}$ \\
\hline $\mathrm{C}_{3} \mathrm{H}_{8} \mathrm{O}$ & $-3.11 \mathrm{E} 08$ & 298.15 \\
\hline $\mathrm{H}_{2} \mathrm{O}$ & $-2.85 \mathrm{E} 08$ & 298.15 \\
\hline $\mathrm{CO}_{2}$ & $-3.94 \mathrm{E} 08$ & 298.15 \\
\hline $\mathrm{O}_{2}$ & 0 & 298.15 \\
\hline $\mathrm{N}_{2}$ & 0 & 298.15 \\
\hline
\end{tabular}

In the above table the formation enthalpies of IPA and water were taken to be those of the liquid state, while that of $\mathrm{CO}_{2}$ was taken to be a gas, representing their initial states.

\subsection{Turbulence Modeling}

FLUENT's renormalization group (RNG) turbulence model ${ }^{3}$ was selected for these calculations because of this model's reported accuracy in recirculating flows. This model follows the two-equation turbulence modeling framework and has been derived from the original governing equations for fluid flow using mathematical techniques called Renormalization Group methods. Based on this mathematical foundation to turbulence transport modeling, as opposed to semiempirical approaches that are more common, the RNG model provides a more general and funda- 
mental model and yields improved predictions of near-wall flow (including flow separation), flows with high streamline curvature and high strain rate, low-Reynolds-number and transitional flow, wall heat/mass transfer, and detailed wake flow and vortex shedding behavior. 


\section{MODAR RUN 920 RESULT COMPARISONS}

\subsection{Temperatures}

\subsubsection{Adiabatic Reaction Temperatures}

Initial simulations of the Run 920 test results showed that using MODAR's test flowrates resulted in near-wall fluid temperatures much lower than the $600^{\circ} \mathrm{C}$ measured, perhaps indicating that some of the test measurements were not accurate. We developed a method to calculate the adiabatic reaction temperature so it could be used to estimate the reactor temperature as a function of flows and temperatures of the input streams; this was determined to be very helpful in establishing sensitivities of reactor temperature to flow parameters and fluid properties.

The adiabatic reaction temperature is defined as the temperature that would be reached if the fuel and oxidant streams mixed and reacted adiabatically. If the heat losses from the reactor are low, as they are in this pilot scale reactor, the steady state (mixed) outlet temperatures predicted by FLUENT will converge to a value very near the theoretical adiabatic reaction temperature.

FLUENT solves the energy equation in terms of conservation of the static enthalpy, $h$, defined as:

$$
h=\sum_{i} m_{i} h_{i}
$$

where

$$
h_{i}=\int_{T_{\text {ref }}}^{T} c_{p, i} d T
$$

where $m_{i}$ is the mass fraction, $T_{\text {ref }}$ is a reference temperature ( $300 \mathrm{~K}$ in these calculations) and $c_{p, i}$ is the specific heat at constant pressure of species $i$. This sensible enthalpy does not include the enthalpy of formation of each species. For chemically reacting flows FLUENT calculates the instantaneous enthalpy, $h^{*}$, as:

$$
\begin{aligned}
h^{*} & =\sum_{i} m_{i}\left[\int_{T_{\text {ref }}}^{T} c_{p, i} d T+\frac{h_{i}^{o}}{M_{i}}+\int_{T_{r e f_{i}}}^{T_{\text {ref }}} c_{p, i} d T\right] \\
& =\sum_{i} m_{i}\left[\int_{T_{\text {ref }}}^{T} c_{p, i} d T+\frac{h_{i}^{o}}{M_{i}}\right]
\end{aligned}
$$

where $h_{\mathrm{i}}^{\circ}$ is the enthalpy of formation of species $i$ obtained at reference temperature $T_{\text {ref }}$ (298.15 K in these calculations; see Table 1, "Enthalpies of formation for HTO species.," on 
page 10), and $M_{i}$ is the molecular weight of species $i$. FLUENT calculates and lists the values of $\mathrm{h}^{*}$ for each cell in the computational domain using the temperatures, compositions, and properties available to it.

We calculate the adiabatic reaction temperature by mixing the instantaneous enthalpies of the core flow and the annular flow (fuel and oxidant, respectively) to obtain a mass averaged instantaneous enthalpy which, in the FLUENT representation, includes the heat of reaction, i. e.,

$$
h_{\text {mixed }}^{*}=\frac{h_{\text {core }}^{*} \dot{m}_{\text {core }}+h_{\text {annulus }}^{*} \dot{m}_{\text {annulus }}}{\dot{m}_{\text {core }}+\dot{m}_{\text {annulus }}}
$$

where $\dot{m}$ is the mass flow rate of the core and annulus.

FLUENT calculates the enthalpy at the core and annulus inlets based upon the model input conditions. Then, using complete oxidation compositions, a temperature is found by trial and error which results in the same mixed enthalpy as calculated above. This is the adiabatic reaction temperature. Using FLUENT to perform the enthalpy calculations we were able to ensure that the properties used and the calculation method matched those in the actual FLUENT runs. Inherent in this calculational method is the assumption of negligible heat transfer from the reaction zone. This is a good assumption because the reactor is well insulated in the upper regions of the reactor bounding the reaction zone. Also, since the lower region has very low flows, there is poor heat transfer between the hot reacticin zone and the cold brine region.

Figure 8 shows the results of our calculations of adiabatic reaction temperatures as a function of both the core stream water flowrate and each of the nozzle exit temperatures. An IPA flowrate of $125 \mathrm{~g} / \mathrm{min}$ was used for all the calculations. MODAR measured a core water flowrate of $1180 \mathrm{~g} / \mathrm{min}$. The calculation results in an adiabatic reaction temperature of $550-575^{\circ} \mathrm{C}$ as opposed to temperatures of about $605^{\circ} \mathrm{C}$ measured in Run 920 .

The inlet boundary conditions were adjusted to get calculated temperatures in the range of the MODAR temperature measurements. The main parameter used to control the reactor temperatures was the core fuel/water ratio. Raising the IPA flow by $10 \%$ was not chosen because air flowrates would also have to have been adjusted. We decided to decrease the core water flow to $1080 \mathrm{~g} / \mathrm{min}$. At the same time we raised the inlet temperatures of both streams by $20^{\circ} \mathrm{C}$ to include the effect of regenerative heating in the inlet nozzle and piping (they were measured outside of the reactor as $30^{\circ} \mathrm{C}$ and $597^{\circ} \mathrm{C}$ for the core and annulus, respectively).

Using a core temperature of $30^{\circ} \mathrm{C}$, an annulus temperature of $620^{\circ} \mathrm{C}$, and a core water flowrate of $1080 \mathrm{~g} / \mathrm{min}$, we predicted ar adiabatic reaction temperature of $609^{\circ} \mathrm{C}$. The results of our FLUENT run showed a peak reaction temperature in the reactor near $605^{\circ} \mathrm{C}$ and an exit temperature of $602^{\circ} \mathrm{C}$. Note that the adiabatic reaction temperature calculations depend upon only the specie flows and temperatures, and the specie specific heats and heats of formation. Reaction kinetics do not affect the adiabatic reaction temperatures but they do affect the distribution and stability of the reaction as discussec later. 


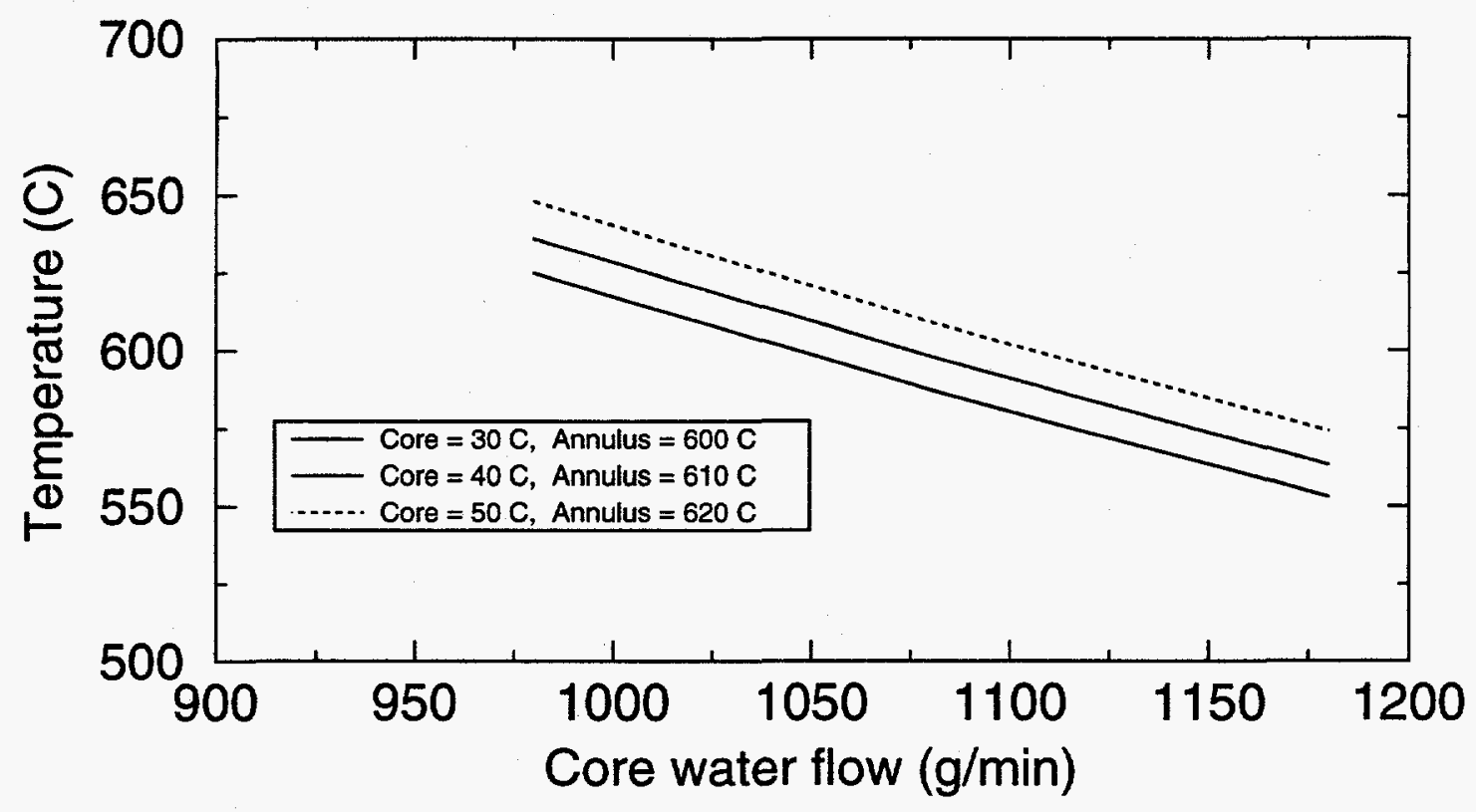

Figure 8. Adiabatic reaction temperatures for MODAR Run $920,125 \mathrm{~g} / \mathrm{min}$ IPA in core, $1305 \mathrm{~g} / \mathrm{min}$ water in annulus

\subsubsection{Fluid Temperatures}

Figure 9 shows the predicted temperature distribution in the entire reactor vessel (note that in this report the scale has been distorted to protect MODAR's confidential geometry and also enhance the clarity of the results by expanding the steep radial gradients). The fluid temperatures are very uniform in the upper half of the reactor outside the reaction zone at a value of about $605^{\circ} \mathrm{C}$. The temperatures decrease relatively linearly as the brine pool is approached. The temperature gradient is steep near the tip of the standpipe where the temperatures are near the critical point. The resultant steep density gradient enhances the stability of the flow near the standpipe. Strong temperature gradients also occur in the cold wall portions of the reactor, including the conical portion and the region right above it.

Figure 10 shows a comparison of the calculated near-wall fluid temperatures with measured values from the MODAR run. Good agreement is seen in the region of the insulated upper region; this is not surprising since the core water flow and inlet temperatures were adjusted to match the calculated exit temperatures with the measured temperatures. In the lower uninsulated section, the agreement is not as good. It appears as though the wall temperature in the lower region is colder than the assumptions used in this study. We did not attempt to get better agreement by adjusting the boundary conditions. The model predictions can be improved by including conducting walls and external heat transfer, along with boundary fitted coordinates in the conical section. 


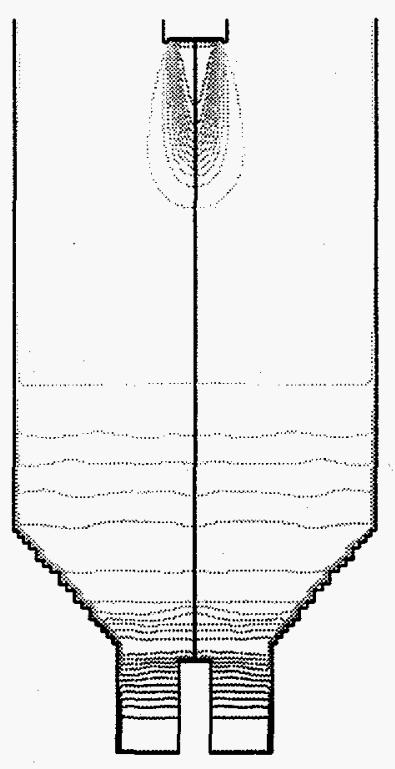

Figure 9. FLUENT predicted fluid temperatures $\left({ }^{\circ} \mathrm{C}\right)$ for MODAR Run 920.

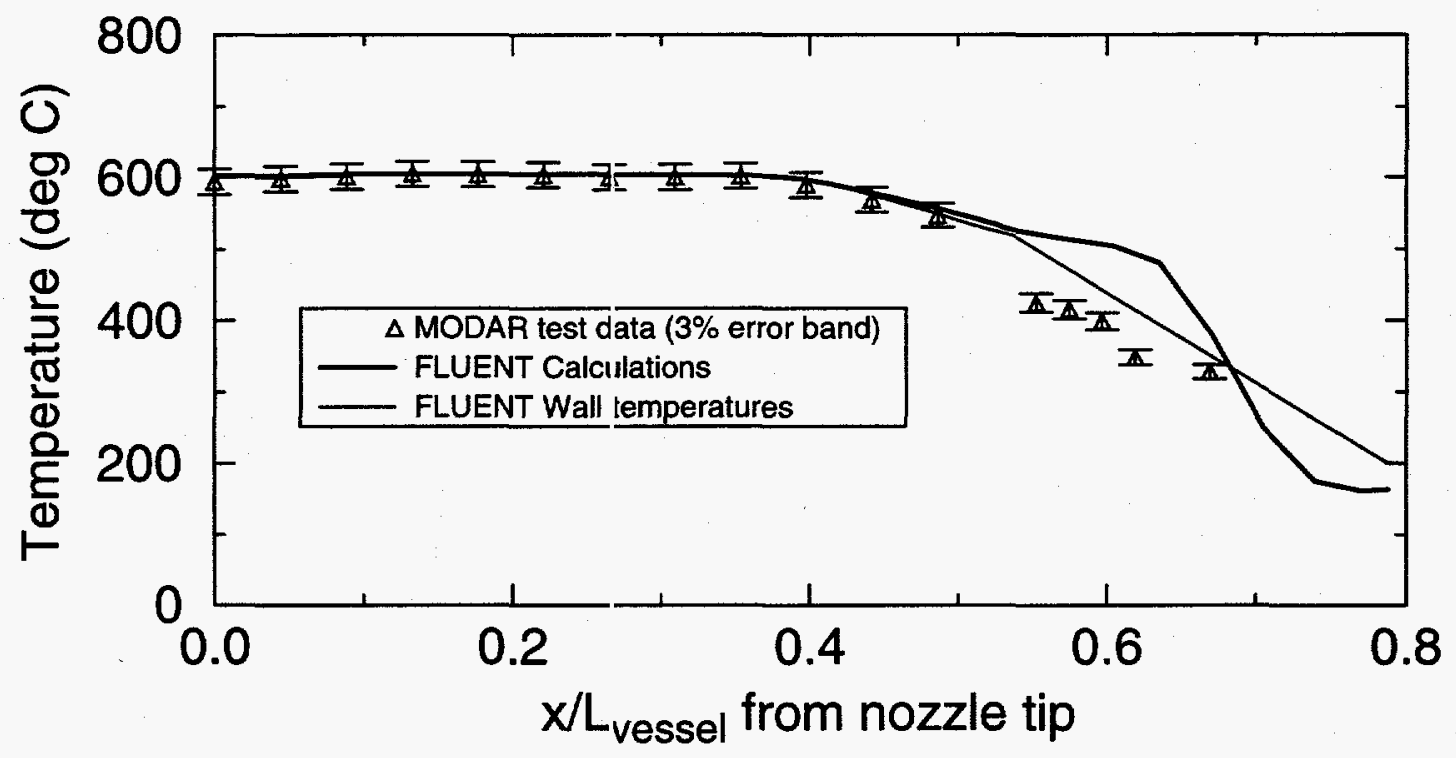

Figure 10. Comparison of MODAR near-wall test data with FLUENT predicted temperatures. 


\subsection{Vessel Reactor Characteristics}

\subsubsection{Recirculation Pattern}

Figure 11 shows the FLUENT predicted stream functions for MODAR Run 920. The lines of constant stream function are defined so that mass is transported along them and not across them. The spacing between streamlines denote regions of equal mass flow. The familiar large recirculating reaction zone is very evident. The lack of lines in the lower regions indicates that there is very little flow in the lower half of the reactor. As will be shown later most of the flow going to the brine pool migrates to the cooler outer wall and travels down along the wall into the pool, setting up a very weak counterrotating flow pattern. A small counterrotating eddy forces much of the outlet flow to flow over the nozzle structure and up into the reactor upper head (not pictured). It is not known whether this small eddy really exists or if it is a result of the assumption of an axisymmetric exit nozzle.

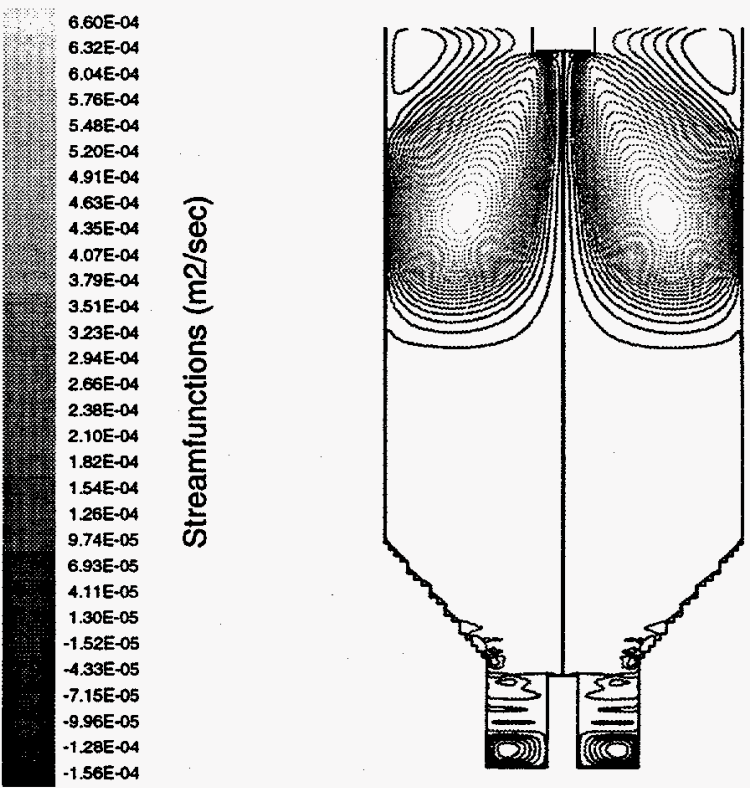

Figure 11. FLUENT predicted streamfunctions for MODAR Run 920.

\subsubsection{Fluid Residence Times}

The FLUENT postprocessing capabilities include a way of visualizing the reactor flowfield by plotting the trajectories of massless particles originating from an arbitrary location. These trajectories are called "streaklines" and are calculated rapidly from an existing flowfield output file. In addition to the starting location of the particles, inputs also include calculation time intervals and number of time steps, thus giving a quantitative indication of the time it takes for these fluid packets to traverse the flow domain. 
The residence time of a fluid particle is the time that it takes to traverse the reactor from the inlet to the exit point. For one-dimensional flow this is simply the volume of the reactor divided by the volumetric flowrate. In a mo:e complicated flowfield such as in this vessel reactor, different portions of the flow have different residence times; it is more accurate to discuss the performance of the reactor in terms of residence time distribution rather than a single value. It is apparent that the average residence time can be defined by an average time for all the various fluid particle trajectories. The minimum sesidence time, however, might be a more important parameter since the particles that remain in the reactor for the shortest time will probably have the poorest chemical destruction.

Figure 12 shows a typical set of streaklines representing a time period of 40 seconds, i. e., from the injection plane to the end of the line the fluid packet has traveled for 40 seconds. (The actual residence time also includes the short time from the nozzle to the injection plane.) Most of the flow in the reactor resides for more than 40 seconds. However, there is a small percentage that originates in the core flow and exits in about 25 seconds; this is the minimum flow residence time indicated by this calculation. This small percentage is seen to circulate once around the primary eddy and quickly exits the reactor. A larger percentage of flow circulates once throughout the top head before it exits; this flow has a residence time of greater than 40 seconds.

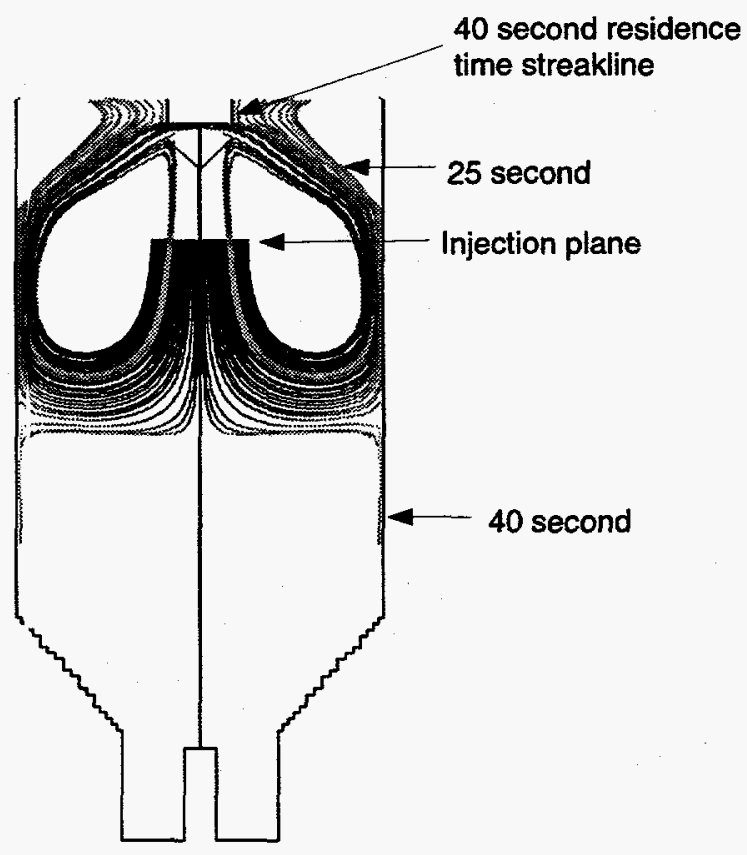

Figure 12. FLUENT predicted streaklines for a 40 second time period. 
The small amount of flow exiting the bottom of the reactor via the brine takeoff has a residence time considerably greater than 40 seconds. This fluid only gets about halfway down the reactor vessel in this time period. This also illustrates the point that the flow that exits at the bottom of the reactor vessel travels down the reactor sidewall rather than in the bulk of the core. This is in a large part due to the large density increase in the fluid as is approaches the cool wall in the lowest part of the reactor. This pulls the low density fluid to the wall much in the same fashion as vapor migrating to a cold condensing wall. As a result the core region below the main eddy is in a nearly stagnant condition.

It is also apparent that a portion of the fluid circulates in the main eddy for a considerably longer period of time than 40 seconds. This portion will have plenty of time for oxidation to occur before it is entrained or mixed with the exiting flow.

These streaklines do not accurately represent the trajectories of particles because they are based upon the assumption of massless particles. We will show the trajectories of actual particles in a later section.

Note also that these streakline calculations are based upon the neglect of the effects of turbulence on the packet trajectories. As will be seen later in this report, turbulence has a major effect on particle trajectories, particularly for the lighter particles. Real fluid particles will not follow the streamlines. Another point to consider is that this vessel reactor was not designed with fluid residence time as the major design parameter. It was sized for salt separation, and, as such, has residence times greater than is needed for organic destruction. This is has an added benefit for a test reactor since it allows a great degree of flexibility in operating conditions while still obtaining a satisfactory destruction efficiency.

\subsubsection{Nozzle Mixing Zone}

The coaxial nozzle used in Run 920 is quite different than the simple coaxial nozzle used in the bench scale model from Run 523.f. This nozzle has a proportionally larger core area with multiple small openings much like a showerhead. The flow essentially dribbles out and is entrained by the higher velocity annular flow of the air/SCW stream. In our model we simplified the core flow by assuming it exited the nozzle uniformly with the appropriate mass flow.

Both the temperatures and the velocities smear out rapidly close to the nozzle and the fuel and oxidizer are well mixed also. Figure 13 is a method of displaying the mixing characteristics downstream of the nozzle. The top half of the plot shows temperature profiles in the mixing zone and indicates the thermal mixing of the core and annular flows (for simplicity the units of the curves are not shown; well mixed flows are indicated by the flat profiles). The bottom half of the plot shows the axial velocity profiles in the same manner. Both halves indicate that the feed fluids are well mixed by a distance of less than one reactor diameter downstream of the nozzle exit.

\subsubsection{Effect of Smoothing the Water Heat Capacity Curve}

As discussed previously, there is a large spike in the heat capacity of water near its critical 


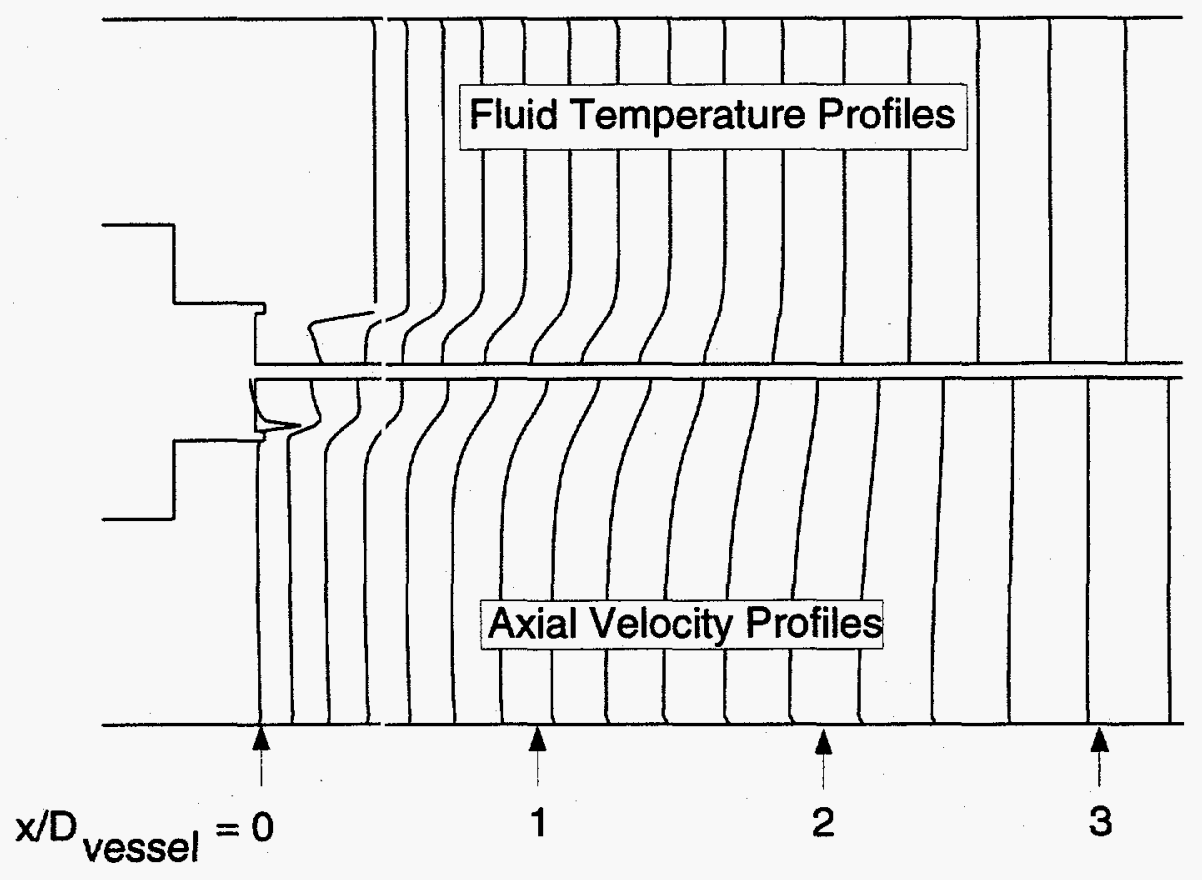

Figure 13. Thermal and hydraulic mixing downstream of nozzle. Flow is well mixed both thermally and hydraulically by about 1 reactor diameter from nozzle.

temperature (about $374^{\circ} \mathrm{C}$ at 3,400 jsia). This sharp property variation makes the CFD solution converge poorly and requires that the specific heat curve be approximated by a smoother curve as discussed in Section 2.3. Figure 14 shows regions whose calculated temperatures lie within the range that are affected by the approximations made to the specific heat curve (between approximately 327 and $427^{\circ} \mathrm{C}$ ).

This figure shows that there are three regions in the reactor that have temperature transitions through this range. These include the near-nozzle oxidation zone in which the low temperature core flow heats up through the critical region due to mixing and oxidation, the region of the brine pool where the cold water pool meets the high temperature reaction products, and the regions near the uninsulated walls where the cold wall meets the high temperature reaction products. The regions where the water properties are approximated are small. In these regions the fluid temperatures are approximate but outside these regions they should be accurate.

The approximation of the water specific heat is not important to the calculated temperatures in most of the reactor (with the assumption, of course, that the integral of the curve, or enthalpy, is correct) but it is important to the stability of the FLUENT calculations. As noted in previous calculations for the bench scale reactor (Reference 2 ), the code will not converge with the true specific heat curve as an input. Indeed, in this study we found that a specific heat curve only slightly more peaked than the input curve ir Figure 7 caused instabilities in the calculations. These insta- 

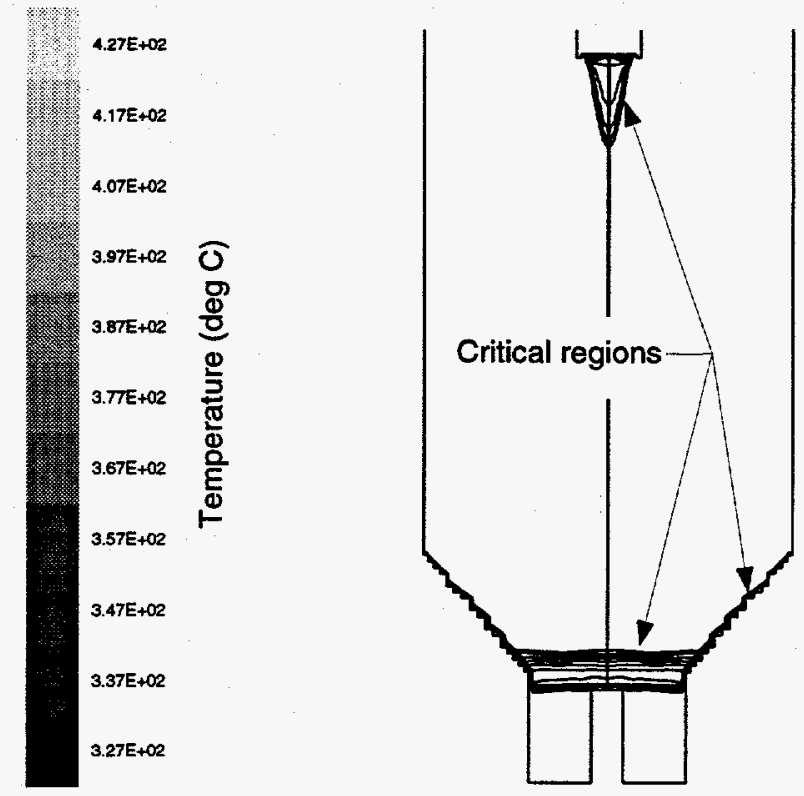

Figure 14. Regions of the reactor with temperatures between $327^{\circ} \mathrm{C}$ and $427^{\circ} \mathrm{C}$ showing the regions of approximate water specific heats. Peak $c_{p}$ is at $379^{\circ} \mathrm{C}$.

bilities are typically manifested as a "blotchy" and unreasonable temperature field and poor convergence characteristics. When smoothed somewhat, the blotchiness disappeared.

Although we have used a single phase fluid model, there are regions in the reactor that have fluids with large density differences. Just downstream of the inlet nozzle, the dense subcritical water is dispersed in the lighter supercritical vapor. Once the mixture temperature reaches $374^{\circ} \mathrm{C}$, the fluid becomes a supercritical fluid. There are also large density differences in the bottom of the reactor. Figure 14 shows that the subcritical regions in the reactor are small so the error introduced is considered to be minimal.

\subsubsection{Arrhenius Reaction Rates}

The effect of Arrhenius rate constant equation on the CFD results needs to be determined. As previously discussed, the rate equation doesn't affect the peak reaction temperatures (as represented by the adiabatic reaction temperatures). If essentially all of the fuel is combusted, the reaction temperatures are determined by the energy input into the system and the effective heat capacities. However, the rate equation does have a direct effect on the reaction distribution (reaction zone shape) and, as such, has a major effect on whether a combination of flows with a given reaction temperature will sustain a stable reaction.

As an example, the Arrhenius constants used as a baseline case for this study (see Section 2.3.2) produced a very stable reaction zone, shown in Figure 15. The high reaction rates (darkest contours) reach to the centerline, indicating that all the waste flow passes through the high reaction zone. We have found that when incomplete reactions occur, the high reaction rates occur on 


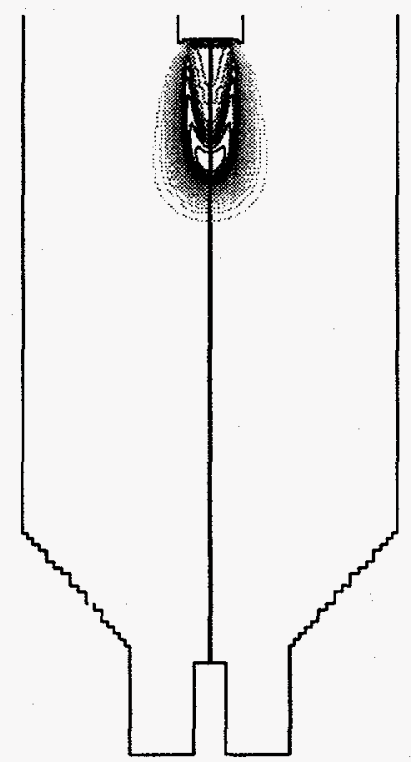

Figure 15. Reaction rate distribution for baseline Arrhenius rate equation for IPA.

the edges of the reaction zone and a low unreacted waste to flow through down the core of the reaction zone. We have also noted that when very high reaction rate curves are used, the reaction zone is very short but it still encloses the waste feed stream and ensures complete oxidation.

In order to quantify the effect of the reaction rates on the CFD calculations, MODAR suggested $^{b}$ that a sensitivity analysis b; performed. We ran the following cases:

Case 1. Baseline MODAR kinetic rate equation.

$$
R_{I P A}=6.801 \times 10^{5} \exp \left(\frac{8.126 \times 10^{7}}{T}\right)\left[C_{I P A}\right]
$$

Case 2. Increase the rate constant by a factor of 10 . This Arrhenius expression produces higher reaction rates in the low :emperature mixing zone.

$$
R_{I P A}=6.801 \times 10^{6} \exp \left(\frac{8.126 \times 10^{7}}{T}\right)\left[C_{I P A}\right]
$$

Case 3. Decrease the rate constant by a factor of 10. This Arrhenius expression produces lower reaction rates in the low temperature mixing zone.

$$
R_{I P A}=6.801 \times 10^{4} \exp \left(\frac{8.126 \times 10^{7}}{T}\right)\left[C_{I P A}\right]
$$


Case 4. Keep the rate at $600^{\circ} \mathrm{C}$ the same as the baseline case and the rate at $375^{\circ} \mathrm{C} 10 \%$ of the baseline case. This Arrhenius expression produces lower reaction rates in the low temperature mixing zone.

$$
R_{I P A}=5.159 \times 10^{8} \exp \left(\frac{1.294 \times 10^{8}}{T}\right)\left[C_{I P A}\right]
$$

The Arrhenius plots for Cases 1-4 are compared graphically in Figure 16 .

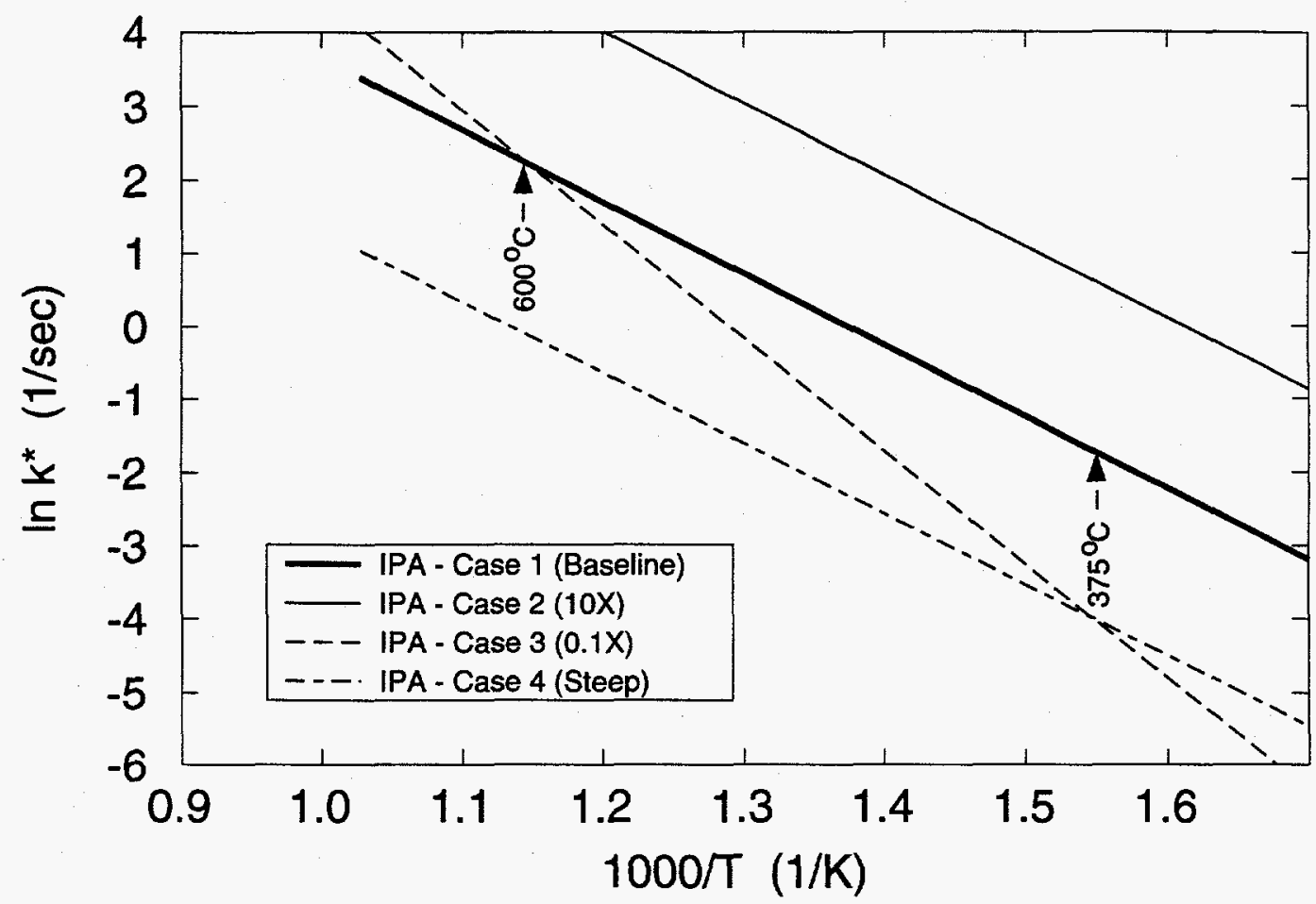

Figure 16. Variations of Arrhenius reaction rate curves considered in this study. MODAR's IPA curve is the baseline. Case 2 is $10 \mathrm{X}$ higher than the baseline. Case 3 is $0.1 \mathrm{X}$ the baseline. Case 4 has a steeper slope with the same value as the baseline at $600^{\circ} \mathrm{C}$ and $0.1 \mathrm{X}$ the baseline at $375^{\circ} \mathrm{C}$.

Figure 17 shows a comparison of the reaction zone shapes for the four cases presented above. This figure delineates the reaction zone by showing both the IPA reaction rates (defined as the rate of creation of IPA) and the IPA mass fractions for each of the four cases. The reaction rate contours are only shown in the range from -0.335 to $0 \mathrm{~kg} / \mathrm{m}^{3}-\mathrm{sec}$ in order to better delineate the outer boundaries of the reaction front. The peak rates, indicated on the figures, range from 4.2 to $-3.4 \mathrm{~kg} / \mathrm{m}^{3}$-sec. The inverse influence of the reaction rate on the reaction zone size is very evident from the plots. 

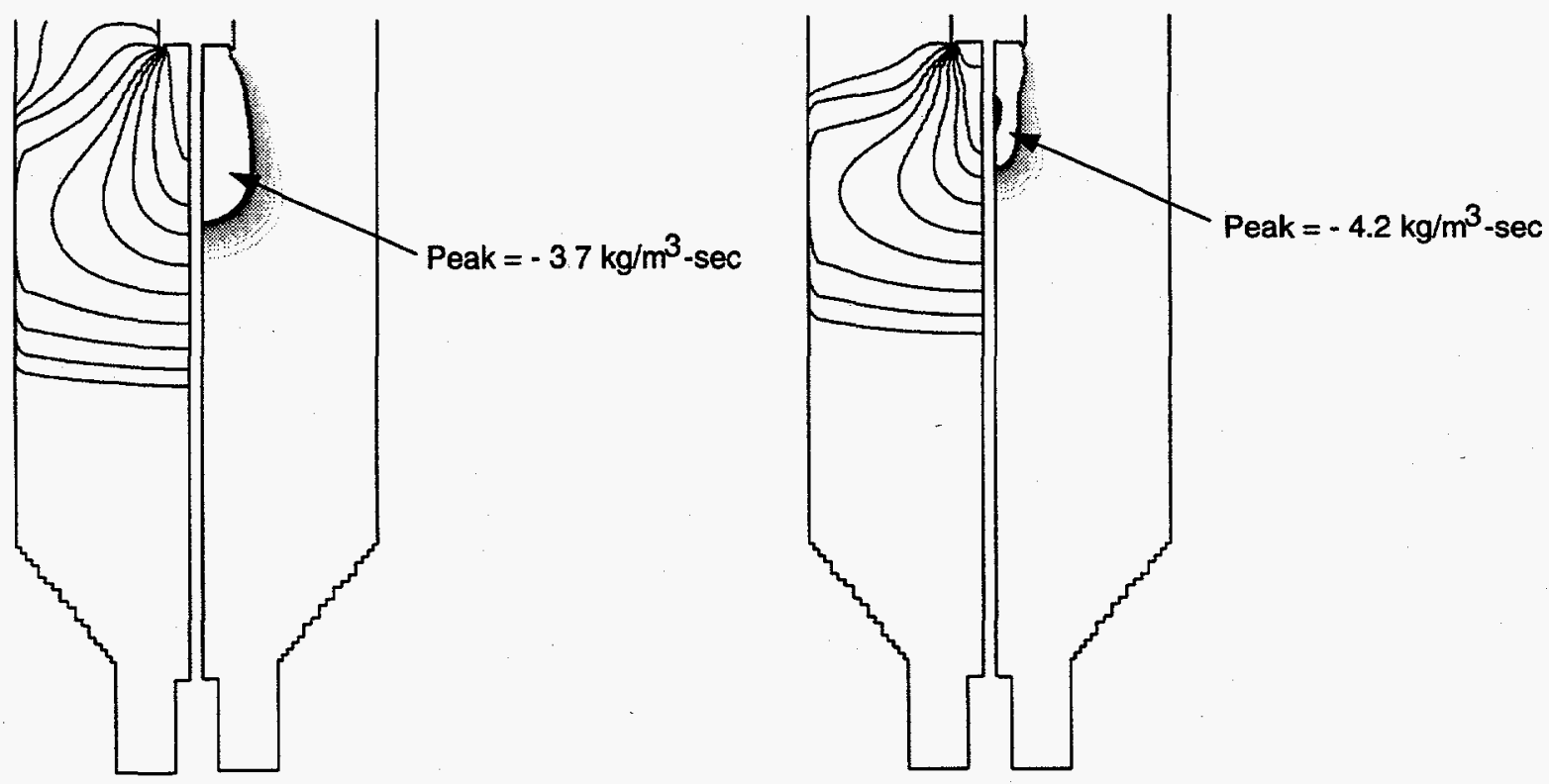

Case 1: Baseline IPA rate

Case 2: 10x Baseline IPA rate
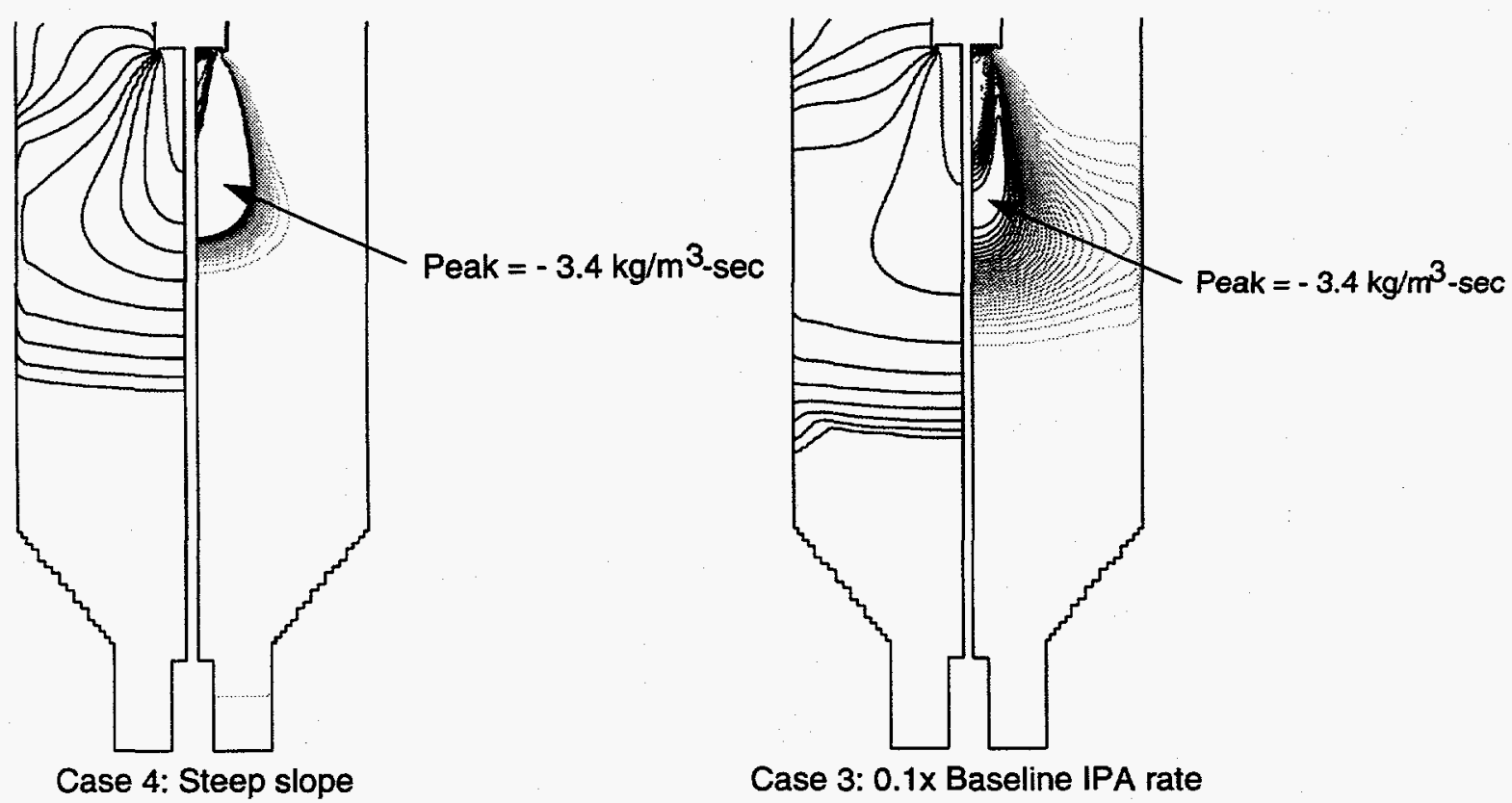

Case 3: 0.1x Baseline IPA rate

Figure 17. Comparison of IPA reartion rates and mass fractions for Cases 1-4. IPA reaction rates are shown in the range from -0.335 to $0 \mathrm{~kg} / \mathrm{m}^{3}-\mathrm{sec}$ and are shown on the right half of each figure. Mass fractions are shown in the range from $10^{-2}$ to $10^{-10}$ and are shown on the left half of each figure. The inlet mass fraction of IPA is 0.1037 . 
The organic destruction efficiency is an important measure of the HTO reactor vessel performance. A related parameter, the IPA mass fraction, can be used to calculate the destruction efficiency. The contours of the IPA mass fraction are shown in the range of $10^{-2}$ to $10^{-10}$. The inlet stream enters the reactor with an IPA mass fraction of 0.1037 and then the IPA concentration is reduced due to oxidation and mixing. The IPA concentration at the bottom of the reactor is seen to be less than $10^{-10}$, the lowest contour shown. The IPA concentration at the upper effluent exit is also less than $10^{-10}$ for Cases 1,2 , and 4 . For Case 3 with the low reaction rates, the exit IPA concentration is still less than $10^{-8}$.

All cases completely oxidize the IPA so the resultant reaction temperatures are essentially the same for the four cases. However, we found that the slope of the rate curve does have an effect on the stability of the solution and sometimes affects whether the reaction front remains stable during the computation. In general, the rate expressions with the lowest activation energies are better behaved and more stable than the more highly activated rates, as would be expected.

\subsubsection{Particle Trajectories}

The solubility of most salts in supercritical water is very low at reaction conditions. They precipitate out in the high temperature oxidation zone, and, since they are typically sticky, they may adhere to the reactor wall upon contact. The crystallization process of salt precipitation in the HTO reactor is not well known but estimates of the locations of salt particle formation can be made. A very useful application of a CFD simulation is to define the trajectories of salt particles once they do precipitate from the high temperature fluid. This can be used to investigate the removal of most of the salt through the brine, and the most likely regions of deposition for the remaining salts on the reactor walls and nozzle.

Figure 12 showed trajectories for massless particles (streaklines) but FLUENT also has the capability of calculating similar trajectories for particles of known sizes and densities. The simplest calculation of particle trajectories, using the mean flow velocities throughout the reactor and including the effects of gravity, is shown in Figure 18. Trajectories were calculated for 5 different diameters assuming a $50 \%$ void $\mathrm{NaCl}$ particle. The injection point was selected in a region where the fluid temperature is between $377-427^{\circ} \mathrm{C}$, near the mixing zone between the core and annulus flows. This method produces smooth trajectories; the effect of turbulence on the particle motion is neglected. For this seed location, the small particles are caught up in the recirculating eddy. The $20 \mu$ particles circulate twice and then exit the reactor, while the $40 \mu$ particles impact the wall near the reactor midsection. The larger particles drop directly to the bottom of the reactor. The trajectories of the smaller particles are highly sensitive to the assumed release location for mean flow calculations. The closer to the nozzle and the further from the centerline that a particle is released, the more likely that it will be trapped in the recirculation zone. Although it is not shown here, there is no mechanism to move particles released on the centerline away from the centerline; all particle sizes drop straight down into the brine.

The particle trajectories calculated without considering turbulence are not accurate. The flow in most of the reactor vessel has a turbulent fluctuating velocity on the same order as the 


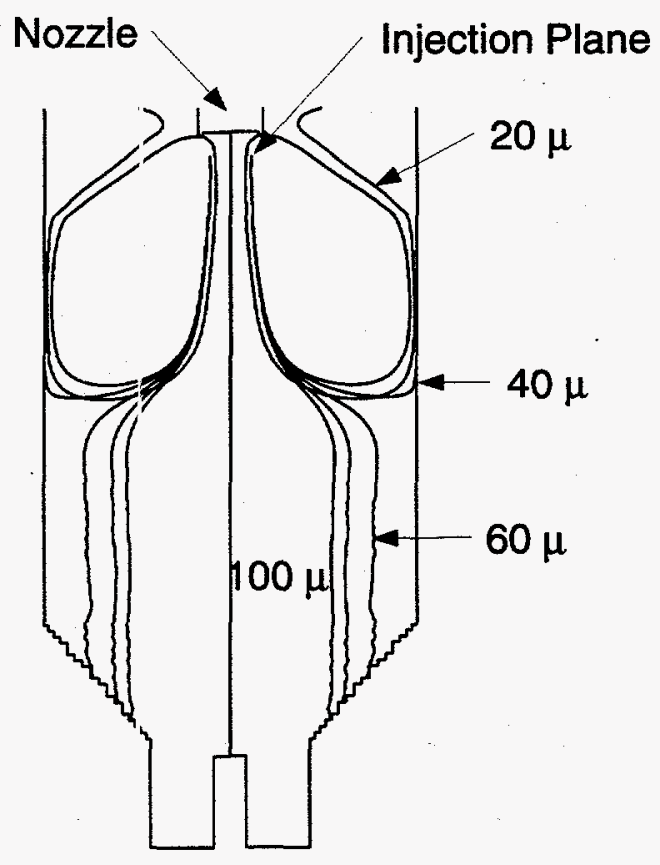

Figure 18. Trajectories of $20,40,60,80$, and $100 \mu$ salt particles precipitating out in the vessel reactor. These calculations use the mean fluid velocities and neglect the effect of turbulence.

mean velocity, i.e., the value of $u^{\prime} / U$ is of the order of 1 . The turbulent fluctuations can have a significant impact on the particle trajectories, especially the smaller ones. FLUENT has the capability of including the random effects of turbulence on the trajectories by using a random-walk approach. This method considers the calculated turbulence scales and randomly includes the effect of turbulence on the particle force balance. Figure 19 shows typical particle trajectories calculated by including the effects of turbulence. It is very evident that there is a significant dispersion of particles. Even particles released on the centerline, as shown here, can easily find their way to the outer walls or even the upper head region and nozzle. Figure 19 shows that the small particles can be transported over the entire upper region of the reactor, while the larger ones still go to the bottom.

There is a significant difference in behavior between the large and small particles when the particles reach the "dead" zone below the main eddy. In this region the velocities are low and sometimes directed upward along the reactor centerline. Essentially all of the net downward flow proceeds down along the cold wall. When small particles reach this zone, they are typically "levitated" and migrate towards the wall. When the larger particles reach the zone they drop straight down through to the bottom.

The results of the turbulent flow particle trajectory calculations are statistical in nature; plotting individual trajectories is not very helpful in analyzing the effect of different particle sizes and release points. To study the effect of particle size and release point on the turbulent trajectories, many trajectories have to be run and the particle impact points summarized. The reactor bound- 


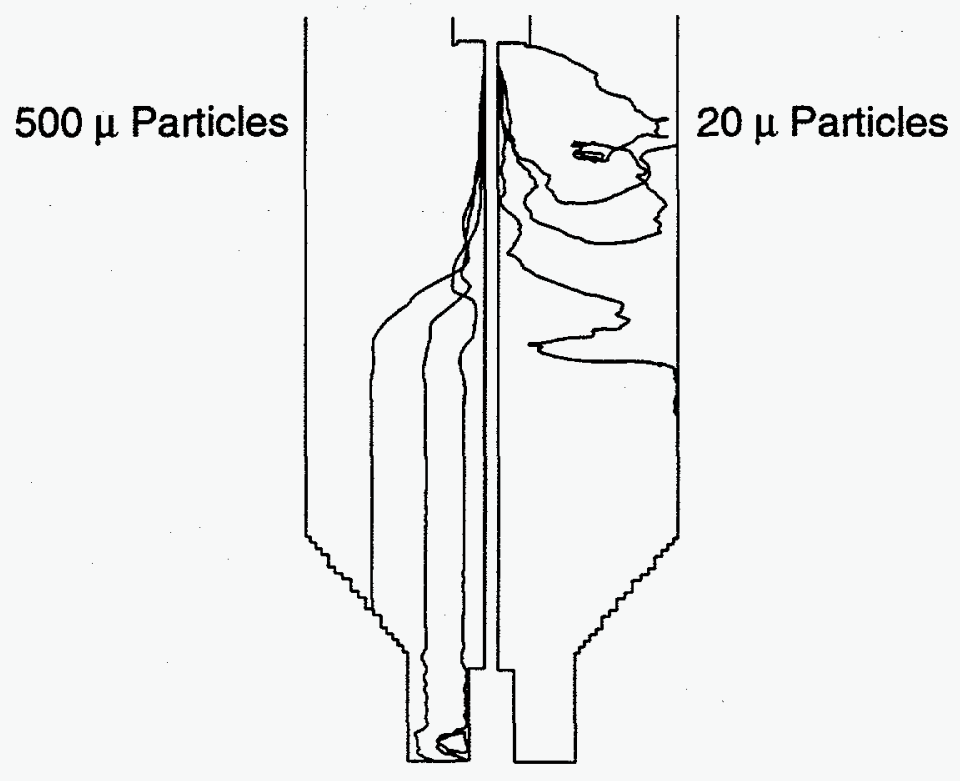

Figure 19. Typical trajectories of three $20 \mu$ (top) and three $500 \mu$ (bottom) particles with the effects of turbulence included. Release point is on reactor centerline.

aries have been subdivided into several regions to receive and tabulate particle impacts. Figure 20 shows the crude discretization of the reactor walls that we used to perform this calculation. Regions selected include the upper reactor region, the top head region, the upper, middle and lower thirds of the cylindrical section, the conical section, the cylindrical brine pool, and the standpipe. This is admittedly crude, but it does allow study of the potential sites of particle dep-

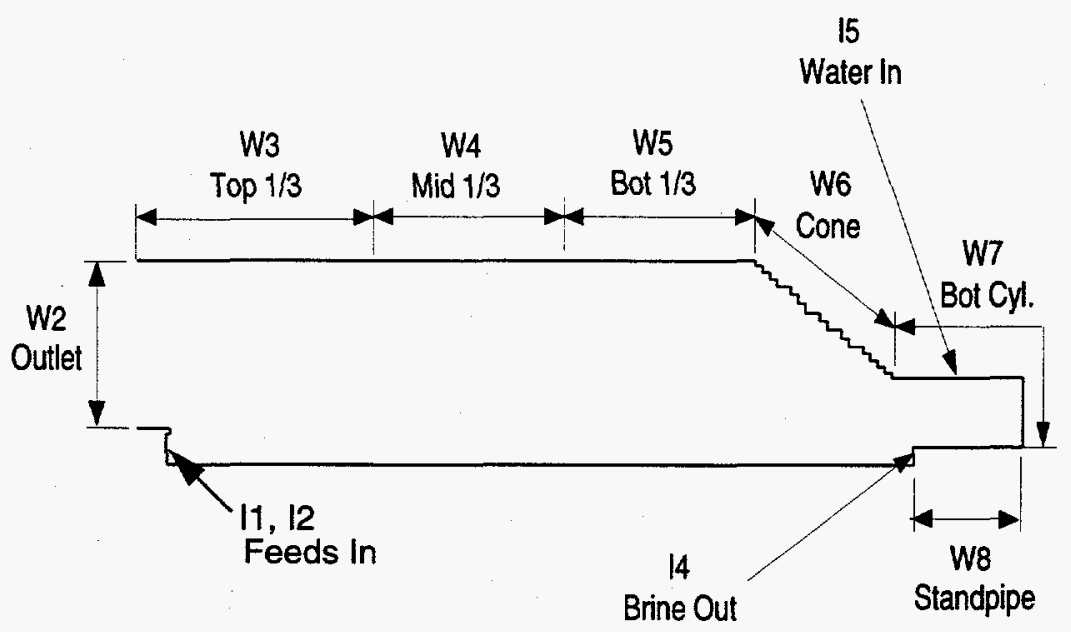

Figure 20. Salt particle impact zones to study the effect of turbulent flow on particle transport. 
osition as parameters are changed. The particle transport wall boundary conditions set into the FLUENT model were such that the prarticle was trapped (i.e., deposited) upon its first impact with the wall. We currently have no data on salt sticking efficiency. Chosing a $100 \%$ sticking efficiency will result in the most conservative salt deposition (i.e., worst case deposits).

Table 2 shows the results as a summary of the number of impacts (there were 100 total for each case run) for 6 particle sizes and 2 injection points. The particle density was taken to be $1000 \mathrm{~kg} / \mathrm{m}^{3}$, which represents a $50 \%$ void $\mathrm{NaCl}$ density. The density of the hot fluid is about 73 $\mathrm{kg} / \mathrm{m}^{3}$ in most of the reactor, save for the colder water regions where the density is about $1000 \mathrm{~kg} /$ $\mathrm{m}^{3}$. The bottom row of the table with the heading "Aborted" represents tries that reach the limiting number of time steps $(200,000$ in this study) without contacting the wall; these are considered to be trapped in the reactor flow. The limiting number of time steps could be increased, or the aborted tries could have been subtracted out and the results renormalized but since there were so few we decided to leave them as FLUENT calculated them. No particle growth was considered.

Table 2. Wall impact summary for $5-1000 \mu 50 \%$ void salt particles. Each column represents a total of 100 tries. Injection location is in nozzle diameters from reactor centerline at an axial location of 1.2 nozzle diameters from the nozzle exit plane.

\begin{tabular}{|c|c|c|c|c|c|c|c|c|c|c|c|c|}
\hline & 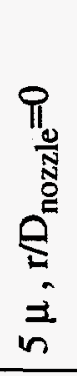 & 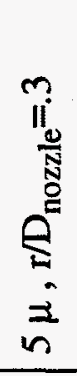 & 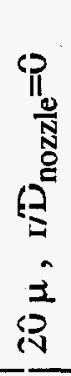 & 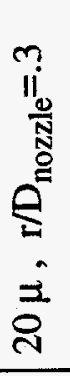 & 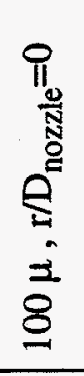 & 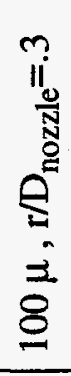 & 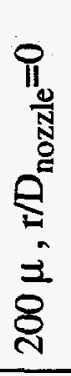 & 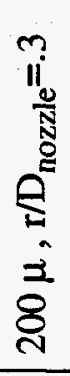 & 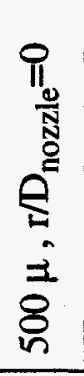 & 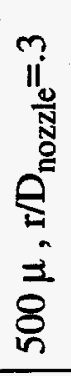 & 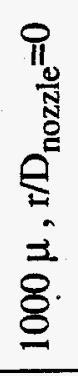 &  \\
\hline W2-Outlet & 3 & 13 & 5 & 4 & 0 & 0 & 0 & 0 & 0 & 0 & 0 & 0 \\
\hline W3-Top $1 / 3$ & 38 & 34 & 35 & 36 & 13 & 23 & 1 & 3 & 0 & 0 & 0 & 0 \\
\hline W4-Mid 1/3 & 56 & 48 & 57 & 53 & 61 & 47 & 28 & 31 & 0 & 0 & 0 & 0 \\
\hline W5-Bot $1 / 3$ & 3 & 4 & 2 & 3 & 0 & 1 & 1 & 4 & 0 & 0 & 0 & 0 \\
\hline W6-Cone & 0 & 0 & 0 & 1 & 24 & 26 & 59 & 49 & 51 & 54 & 7 & 22 \\
\hline W7-Brine cylinder & 0 & 0 & 0 & 0 & 2 & 2 & 10 & 7 & 44 & 42 & 80 & 68 \\
\hline W8-Standpipe & 0 & 0 & 0 & 0 & 0 & 0 & 0 & 1 & 2 & 1 & 6 & 7 \\
\hline I4-Brine outlet & 0 & 0 & 0 & 0 & 0 & 0 & 0 & 1 & 3 & 1 & 7 & 3 \\
\hline I5-Brine inlet & 0 & 0 & 0 & 0 & 0 & 1 & 1 & 3 & 0 & 1 & 0 & 0 \\
\hline Aborted & 0 & 0 & 1 & 3 & 0 & 0 & 2 & 1 & 0 & 1 & 0 & 0 \\
\hline
\end{tabular}

This table shows several important characteristics of the salt particle transport. First, the results confirm expectations that the smaller particles are more likely to find their way to the 
upper regions of the reactor than the larger particles. Particles less than $20 \mu$ do not reach locations below about the midpoint of the reactor, while particles greater than $500 \mu$ do not impact higher than the conical section as discussed previously in this report. Middle size particles can impact in the middle sections of the reactor. Only particles $20 \mu$, or smaller, reached the top head and inlet nozzle structure.

The difference in radial injection point showed a small effect on salt particle impact points. The closer to the centerline that the particles were released, the lower in the reactor the salts tended to fall. For $1000 \mu$ particles, injecting them further out resulted in more impacting on the cone rather than falling into the brine cylinder. However, contrary to the laminar flow calculations, even particles injected on the centerline can impact the sidewalls due to the effects of turbulence.

Neither small or large particles deposit on the lower 1/3 of the cylinder (W5), albeit for different reasons. The smaller particles could not penetrate into the "dead" region below the main eddy as they are effectively suspended until they (randomly) contact the wall above W5. Large particles proceed into the low velocity region and dropped straight down into the bottom of the reactor. These trajectory characteristics are shown in the typical traces in Figure 19.

Although the FLUENT model can utilize a prespecified particle size distribution, these calculations were simplified by considering only a single particle size. It is difficult to relate these results to available test results because the particle size distribution in actual runs is unknown and typical tests accumulate deposits over a period of several hours, resulting in a time dependence of salt deposits that cannot be evaluated in post-test examinations. Also, if the deposition of salt is significant, the geometry and flow patterns could be changing during the test run.

Another shortcoming of particle tracing is the omission of particle growth and agglomeration. The particles that make their way into the main circulation zone will tend to grow with time. As the particles get larger they will tend to find their way towards the lower sections of the reactor. The salt deposition described in Table 2 represents a worst case scenario. Inclusion of particle growth will result in a large fraction of the solids being removed via the brine. 


\section{CONCLUSIONS AND RECOMMENDATIONS}

The current HTO vessel reactor CFD model has evolved considerably from that used in the bench scale study of Reference 1 . Areas of significant improvement include better fluid thermal and transport properties, a better water specific heat approximation, use of FLUENT's multigrid solver option to speed convergence, addition of heat transfer to the surroundings, and inclusion of the effect of the vessel reactor brine pool and brine takeoff. The new calculations of adiabatic reaction temperatures have proven to be invaluable in establishing the sensitivities of changes in inlet conditions on reactor temperature before a full CFD simulation is made. Also, a valuable tool was provided by FLUENT which allows calculation of the volume integral of the heat release for comparison with theoretical heat content of the waste flow as the calculations proceed. This parameter gives an early indication of an unmaintainable oxidation front; this is much more efficient than simply monitoring the tenıperature domain as was done in the past.

The predicted temperatures of the near wall fluid (these are the only measurements available for comparison) compare reasonably well with the limited data taken in this region. Both the data and the calculations indicate that the near-wall temperatures in the reaction zone are very uniform, making their use in verifying the model difficult. The reaction front zone has steeper gradients and would be better for validation data but measurements in the core are more difficult.

We still have a discrepancy with the test measurements; we have to use a lower core water flow than MODAR reports to achieve comparable exit temperatures. As discussed before, this is independent of the kinetics and is calculated from a relatively simple energy balance. Possible reasons for the mismatch include:

1. Uncertainty in experimental feed flows and temperatures

2. Non-ideal effects of mixlure properties: All specie properties were obtained for pure components. Mixture properties were calculated from the equations stated earlier for a non-ideal gas assuming complete mixing. These mixing rules may not be accurate for fluids near the critical point. Uncertainties in properties will affect both the FLUENT results and the adiabatic reaction temperature calculations.

Until this issue is resolved, it $i$; felt that the flow adjustment used in these calculations will provide a reasonable estimate of the flows and temperature fields in the HTO reactor.

Another uncertainty in the boundary conditions is the wall temperature distribution. To address this we plan to improve our model in the following areas:

1. Use boundary fitted coordinates (BFC) to model the conical lower section of the reactor rather than the stair-stepped approach used herein. This will provide a smoother representation of this reg,ion and may effect the local circulation pattern.

2. Once a BFC model is developed, we can incorporate a conducting wall to include the effects of axial conduction. At the same time, external heat transfer can be included in the model. With these additions the model can be used to calculate the wall tempera- 